\section{EDITORIALS}

495 Reports on pyschotherapy commissioned by the National Health Service Executive A. Obholzer

497 Liver transplantation for alcoholic liver disease

L. Howard and T. Fahy

501 Eugeria, longevity and normal ageing K. Ritchie

\section{REVIEW ARTICLES}

502 Excess mortality of schizophrenia.

A meta-analysis

S. Brown

509 Costs of schizophrenia

M. Knapp

\section{PAPERS}

519 Minor psychiatric disorder in NHS trust staff: occupational and gender differences

T. D. Wall, R. I. Bolden, C. S. Borrill, A. J. Carter, D. A. Golya G. E. Hardy, C. E. Haynes, J. E. Rick, D. A. Shapiro and M. A. West

524 Brazilian multicentric study of psychiatric morbidity. Methodological features and prevalence estimates N. Almeida-Filho, J. J. Mari, E. Coutinho, J. F. França, J. Fernandes, S. B. Andreoli and E. A. Busnello

530 Urban environment and mental health.

A longitudinal study

O. S. Dalgard and K. Tambs

537 Determinants of general practitioner recognition of psychological problems in a multi-ethnic inner-city health district S. M. Odell, P. G. Surtees, N.W. J. Wainwright, M. J. Commander and S. P. Sashidharan

542 Prevalence and significance of weight and shape concerns in girls aged $11-16$ years P. J. Cooper and I. Goodyer

545 Family functioning and life events in the outcome of adolescent anorexia nervosa C. North, S. Gowers and V. Byram
550 Postnatal depression and elation among mothers and their partners: prevalence and predictors

A. Lane, R. Keville, M. Morris, A. Kinsella, M. Turner and S. Barry

556 Trends in deliberate self-harm in Oxford, 1985-1995. Implications for clinical services and the prevention of suicide K. Hawton, J. Fagg, S. Simkin, E. Bale and A. Bond

561 Suicide among psychiatric in-patients in a changing clinical scene. Suicidal ideation as a paramount index of short-term risk H. G. Morgan and R. Stanton

564 One-year, low-dose neuroleptic study of in-patients with chronic schizophrenia characterised by persistent negative symptoms. Amisulpride $v$. haloperidol J. C. Speller, T. R. E. Barnes, D. A. Curson, C. Pantelis and J. L. Alberts

569 Sulpiride augmentation in people with schizophrenia partially responsive to clozapine. A double-blind, placebocontrolled study

R. Shiloh, Z. Zemishlany, D. Aizenberg, M. Radwan, B. Schwartz, P. Dorfman-Etrog, I. Modai, M. Khaikin and A. Weizman

574 Altered dopaminergic function and negative symptoms in drug-free patients with schizophrenia. [ $\left.{ }^{123} \mid\right]$-iodobenzamide SPECT study

M. B. Knable, M. F. Egan, A. Heinz, J. Gorey, K. S. Lee,

R. Coppola and D. R. Weinberger

578 Test of $\times$ q26.3-28 linkage in bipolar and unipolar affective disorder in families selected for absence of male to male transmission

C. Smyth, G. Kalsi, J. Brynjolfsson, J. O'Neill, D. Curtis. L. Rifkin, E. Moloney, P. Murphy, H. Petursson and H. Gurling

\section{COLUMNS}

582 Correspondence

587 One hundred years ago

588 Corrigendum

589 Book reviews

597 Contents of The American Journal of Psychiatry 


\section{Debbie doesn't know that Cipramil}

is now indicated for panic disorder
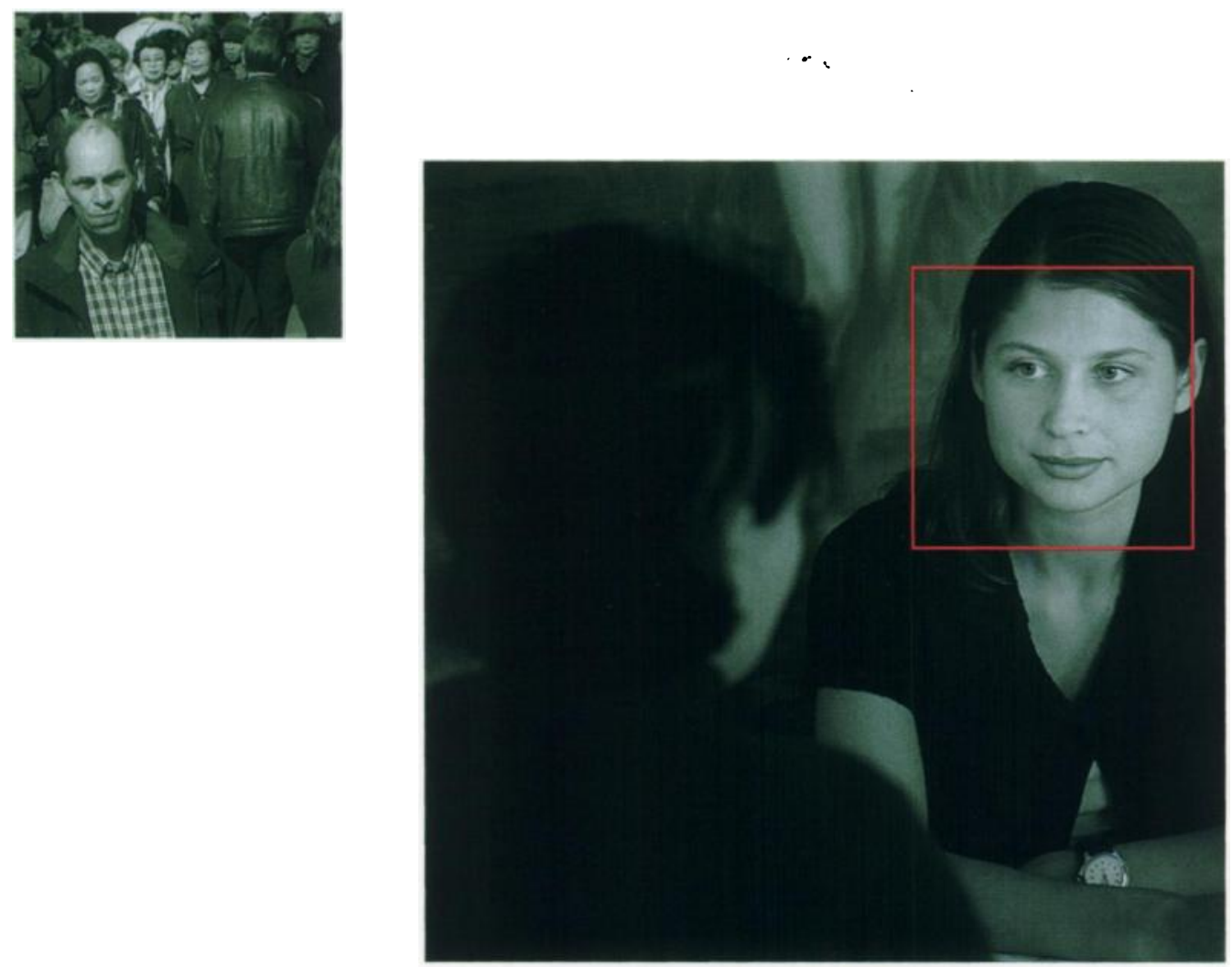

\section{... she just knows her doctor}

\section{made a logical choice}

As a patient with Panic Disorder, Debbie is beginning to appreciate the value of the Cipramil treatment that her doctor has newly prescribed.

Of course, Debbie would no more talk of the recently extended indication for Cipramil than its high selectivity ${ }^{1.2}$, good tolerability ${ }^{3}$, and low risk of drug interactions ${ }^{4.5 .6}$. She just recognises the difference that Cipramil makes to the stability and quality of her life.

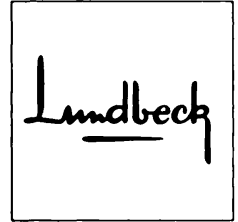

\section{Cipramil citalopram now indicated for panic disorder}

Presentation: 'Cipramil' tablets $10 \mathrm{mg}: \mathrm{PL} \mathrm{0458/0057,} \mathrm{each} \mathrm{containing} 10 \mathrm{mg}$ of citalopram as the hydrobromide. 28 (OP) $10 \mathrm{mg}$ tablets $\mathrm{f} 12.77$. 'Cipramil' tablets $20 \mathrm{mg}:$ PL $0458 / 0058$, each containing $20 \mathrm{mg}$ of citalopram as the hydrobromide. 28 (OP) $20 \mathrm{mg}$ tablets 221.28. Indications: Treatment of depressive illness in the initial phase and as maintenance against relapse/recurrence. Treatment of panic disorder, with or without agoraphobia. Dosage: Irooting depression: Aduts: $20 \mathrm{mg}$ a day. Depending upon individual patient response, this may be increased in $20 \mathrm{mg}$ increments to a maximum of $60 \mathrm{mg}$. Tablets should not be chewed, and should be taken as a single. oral daily dose, in the morning or evening without regard for food. Treatment for at least 6 months is usually necessary to provide adequate maintenance against the potential for relapse. Trooting ponk disonders $10 \mathrm{mg}$ daity for the first week, increasing to $20 \mathrm{mg}$

daily. Depending upon individul 4 patient response, dosape may be further increased to a maximum of $60 \mathrm{mg}$ daily.

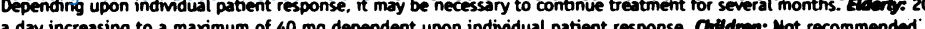

cardiac arrhythmias. Do not use with or within 14 days of MAO inhibitors: leave a seven day gap before starting MAO inhibitor treatment. Use a low starting dose for panic disorder, to reduce the likelihood of an initial anxiogenic effect (experienced by some patients) when starting pharmacotherapy. Drug Interactions: MAO inhibitors (see Precautions). Use lithium and tryptophan with caution. Routine monitoring of lithium levels need not be adjusted. Adverse Events: Most commonly nausea, sweating, tremor, somnolence and dry mouth. With citalopram, adverse effects are in general mild and transient. When they occur, they are most prominent during the first two weeks of treatment and usually attenuate as the depressive state improves. Ovondosage: Symptoms have included somnolence, coma, sinus tachycartia, occasional nodal inythm, episode of grand mal comvision, nausea, vomiting, sweating and hyperventilation. No specific

antidote. Treatment is symptomatic and supportive. Early gastric lavage suggested. Legal Catagery: POM 24.1.95.
Further information available upon request. Product licence holder: Lundbeck Ltd., Sunningdale House, Caldecotte Lake Further information available upon request. Product licence holder: Lundbeck Ltd., Sunningdale House, Caldecotte Lake
Business Park, Caldecotte, Milton Keynes, MK7 8LF. (1) 'Cipramil' is a Registered Trade Mark. (1) 1997 Lundbeck Ltd. Date 


\section{CIDI-Auto 2.I}

Computerised version of the Composite International Diagnostic Interview v2.I for epidemiological and clinical research, and for clinical support for ICD-ro and DSM-IV diagnoses.

Program, manual and training video US\$ 500, Stg 320.

World Health Organization Collaborating Centre: 299 Forbes Street, Darlinghurst, NSW, Australia 2010.

Fax: +61 293324316

E-mail: judyo@crufad.unsw.edu.au http://www.unsw.edu.au/clients/crufad/ home.htm

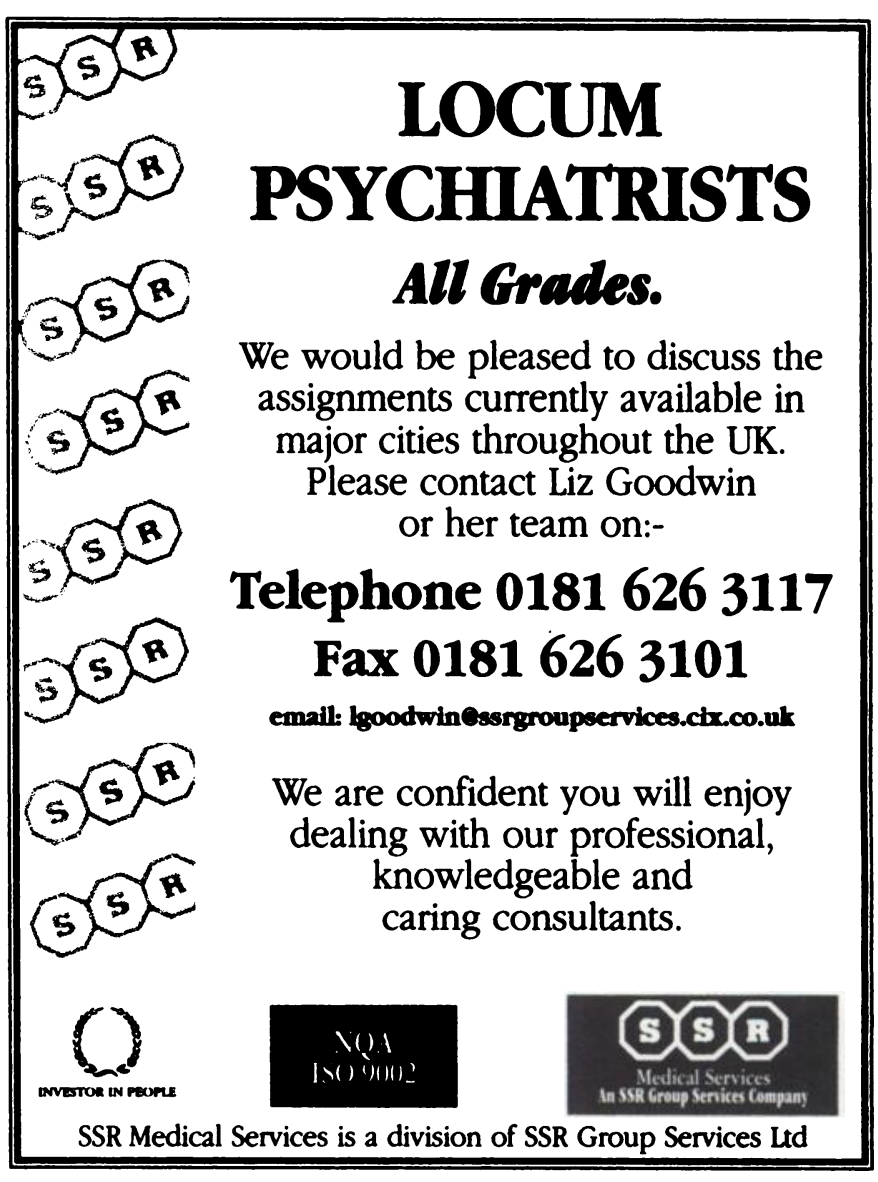

\section{The Royal College of Psychiatrists \\ St) Journal of Continuing Professional Development \\ Advances in Psychiatric Treatment}

Editor: Andrew Sims, Professor of Psychiatry,

St James's University Hospital, Leeds

Subscription rate for Volume 3, 1997 (6 issues):

Europe, including UK $£ 70.00$

USA US $\$ 110.00$ Elsewhere $£ 70.00$

Full airmail $£ 6 / \$ 10$ extra

$A P T$ with CPD registration $£ 85.00$

Dr. Elliot Goldner, Psychiatric Director, Eating Disorder Program, St. Paul's Hospital, 1081 Burrard Street, Vancouver, B.C. Canada V6Z 1 Y6. Tel: (604) 631-5702; fax: (604) 631-5631; e-mail: goldnee@unixg.ubc.ca

UNIVERSITY OF BRITISH COLUNIBIA ST. PAUI'S HOSPITAL.
To enter your subscription or to obtain a sample copy of APT, contact: Publications Subscription Department, Royal Society of Medicine Press Limited, PO Box 9002, London W1M 0ZA, UK. Tel: +44(0)171 290 2927/8; Fax: +44( 0)1712902929

Please note: College members wishing to receive APT and register for $C P D$ should contact the Registration Department, Tel: +44(0)1712352351 


\section{Direct Medical Appointments}

The Consultants Choice

\section{LOCUM positions available NOW}

Long or Short Term

Top Rates

All areas of the UK

\section{Choice of Quality Consultant Posts}

\section{Documentation/Visa arranged}

\section{Permanent and Substantive Positions}

CALL NOW FOR A PROFESSIONAL SERVICE

$$
\begin{aligned}
& \text { Tel: +44 (0) I792 } 472525 \\
& \text { Fax: + } 44 \text { (0) I } 792472535
\end{aligned}
$$

E-mail: medical.appointments@cyberstop.net

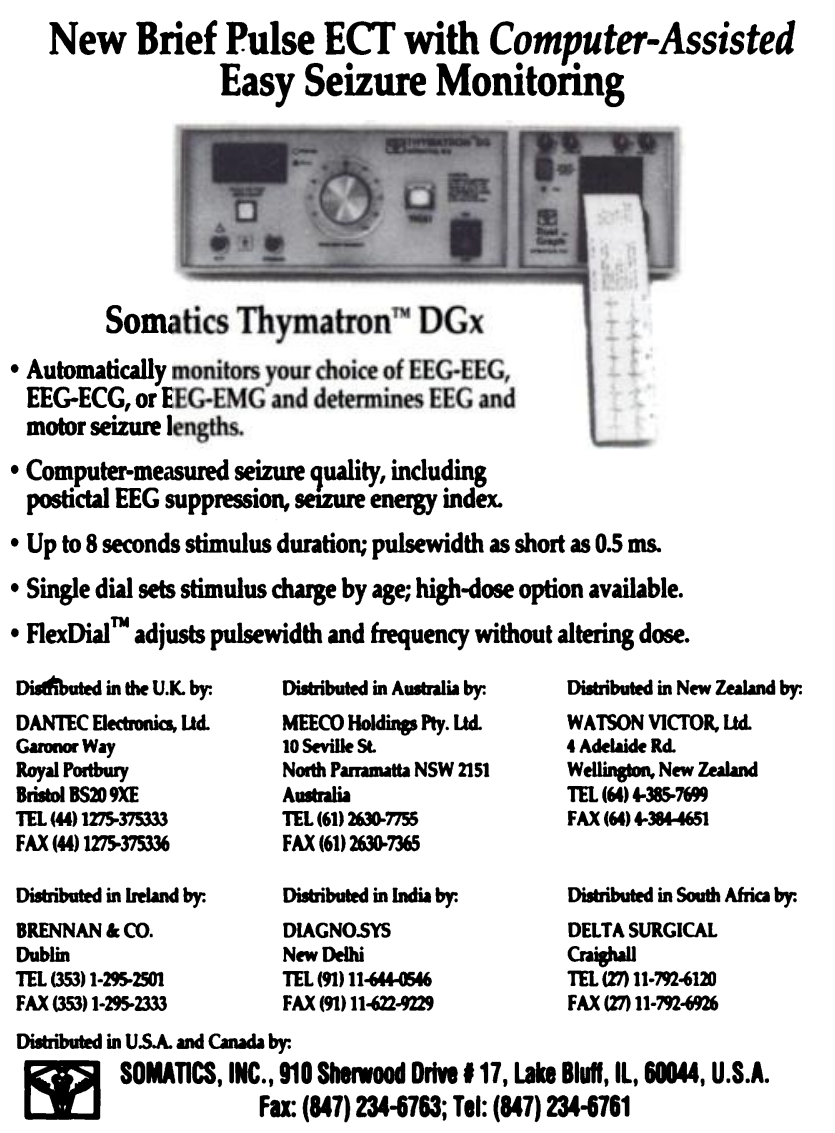

\section{MENTAL HEALTH IN CHINA 6- 21 JUNE 1998}

This study tour represents a rare opportunity to observe Chinese psychiatric services. This is the first time a tour of this nature has been permitted to visit a range of mental health institutions in China. Mental Health in China allows participants to visit a range of poychiatric services in Beljing, $X i a n$ and Chongqing.

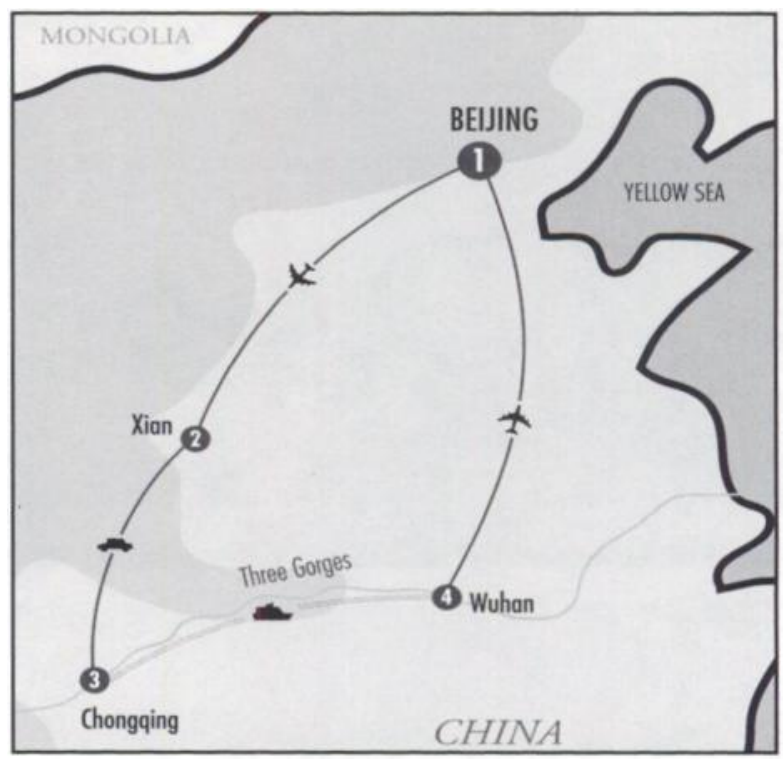

This unique opportunity is combined with the chance to experience the ancient culture of this country from the Great Wall to the Forbidden City, Summer Palace, Tiananmen Square and the Terracotta Warriors. The tour culminates in a four day cruise down the Yangtze river and through the huge Three Gorges, one of the wonders of the world

This may be the last opportunity to see the Three Gorges. When the new dam under construction is finished, the water level will rise flooding the Three Gorges.

Mental Health in China will be of interest to psychiatrists, psychologists and psychiatric nurses. Partners or non-medical participants are welcome.

The group will be escorted throughout the tour by Harry Field who has a wide understanding of both British and Chinese psychiatric services, together with an interpreter and local guides. This is an opportunity that should be taken before China changes forever. The fully inclusive price is $€ 2,695$.

For full details on the tour telephone Master Travel on 0181671 7521, fax 0181671 7327, Harry Field on 01819402493 or fill in the form below and send to Master Travel, FREEPOST(SE7045), London SE24 9BR Email master.travel@MarkAllenGroup.com

Web site at http://wwwMarkAllenGroup.com/Mtravel.htm

MENTAL HEALTH STUDY TOUR TO CHINA 1998 NAME:

ADDRESS: 


\title{
Wasn't late getting up
}

\section{Didn't let fish off hook}

\author{
Didn't fall in water
}

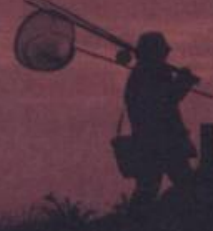

Didn't have a seizure

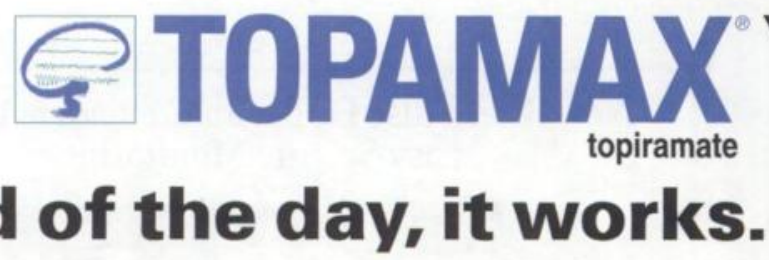

\section{At the end of the day, it works.}

\section{Adjunctive treatment for partial seizures with or without secondary generalisation}

\section{TOPAMAX Abbreviated Prescribing Information}

\section{Please read the data sheet before prescribing}

Presentation: Tablets each imprinted "TOP" on one side and strength on the other containing $25 \mathrm{mg}$ (white), $50 \mathrm{mg}$ (light yellow), $100 \mathrm{mg}$ (yellow), and $200 \mathrm{mg}$ (salmon) topiramate. Uses: Adjunctive therapy of partial seizures, with or without secondarily generalised seizures, in patients inadequately controlled on conventional first line antiepileptic drugs. Dosage and Administration: Adults and Elderly: Oral administration. Usual dose: $200 \mathrm{mg}-400 \mathrm{mg} / \mathrm{day}$ in two divided doses. Maximum recommended dose: $800 \mathrm{mg} /$ day. Initiate therapy at $50 \mathrm{mg}$ bd then titrate to an effective dose. See data sheet for titration. Do not break tablets. It is not necessary to monitor topiramate plasma concentrations. Patients with renal disease/haemodialysis may require. a modified titration schedule. (See data sheet). Children: Not recommended Contra-indications: Hypersensitivity to any component of the product. Precautions and Warnings: Withdraw all antiepileptic drugs gradually. Maintain adequate hydration to reduce risk of nephrolithiasis (especially increased in those with a predisposition). Drowsiness likely. TOPAMAX may be more sedating than other antiepileptic drugs therefore caution in patients driving or operating machinery. particularly until patients' experience with the drug is established. Do not use in pregnancy unless potential benefit outweighs risk to foetus. Women of child bearing potential should use adequate contraception. Do not use if breastfeeding. Interactions: Other Antiepileptic Drugs: No clinically

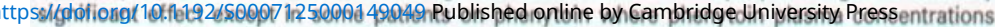
may increase. Phenytoin level monitoring is advised. Effects of other antiepileptic drugs: Phenytoin plasma concentrations on sodium valproate addition or withdrawal. Digoxin: A decrease in serum digoxin occurs. Monitor serum digoxin on addition or withdrawal of TOPAMAX. Oral Contraceptives: Should contain not less than $50 \mu \mathrm{g}$ of oestrogen. Ask patients to report any change in bleeding patterns. Others: Avoid agents predisposing to nephrolithiasis. Side Effects: In 5\% or more: ataxia, impaired concentration, confusion, dizziness, fatigue, paraesthesia, somnolence and abnormal thinking. May cause agitation and emotional lability (which may manifest as abnormal behaviour) and depression. Less commonly: amnesia, anorexia, aphasia, diplopia, nausea, nystagmus, speech disorder, taste perversion, abnormal vision and weight decrease. Increased risk of nephrolithiasis. Venous thromboembolic events reported - causal association not established. Overdosage: If ingestion recent, empty stomach. Activated charcoal not recommended. Supportive treatment as appropriate. Haemodialysis is effective in removing topiramate. Pharmaceutical Precautions: Store in a dry place at or below $25^{\circ} \mathrm{C}$. Legal Category: POM Package Quantities and Prices: Bottles of 60 tablets. 25mg (PL0242/0301) $=£ 22.02 ; 50 \mathrm{mg}(\mathrm{PL} 0242 / 0302)=£ 36.17 ; 100 \mathrm{mg}$ $($ PL0242/0303) $=\mathrm{f64.80;200mg} \mathrm{(PL0242/0304)}=\mathrm{f} 125.83$.

Product Licence Holder: JANSSEN-CILAG LIMITED, SAUNDERTON, HIGH WYCOMBE, BUCKINGHAMSHIRE HP14 4HJ. API VER 210397.

Further information is available on request from the Marketing Authorisation Holder: Janssen-Cilag Limited, Saunderton, High Wycombe, Buckinghamshire HP14 4HJ. (3) Registered Trademark C Janssen-Cilag Limited 1997 


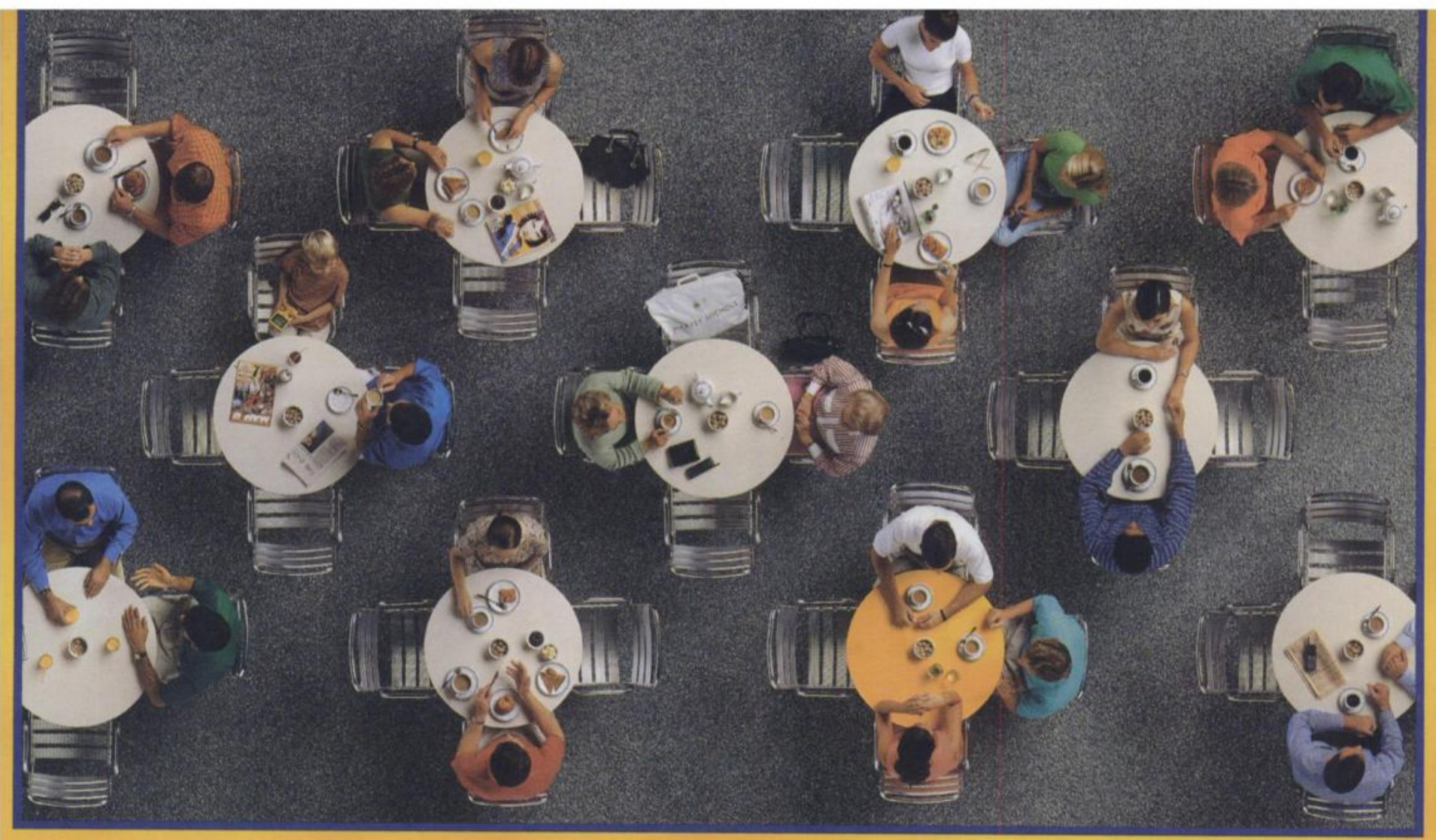

\section{Add life to living with schizophrenia}

Solian is a new benzamide antipsychotic, with the ability to treat both the positive ${ }^{1}$ and negative ${ }^{2}$ symptoms of schizophrenia.

Solian offers a lower incidence of EPS than standard neuroleptics such as haloperidol, ${ }^{3}$ as well as avoiding some of the drawbacks of certain atypicals: it does not require routine cardiovascular ${ }^{4,5}$ or haematological $\left.\right|^{4,6}$ monitoring and patients gain significantly less weight than those treated with risperidone. ${ }^{2}$

So when patients need the ability to cope with their condition, Solian has the power to treat their positive ${ }^{1}$ and their negative ${ }^{2}$ symptoms whilst still allowing them to do the everyday things that the rest of us take for granted.
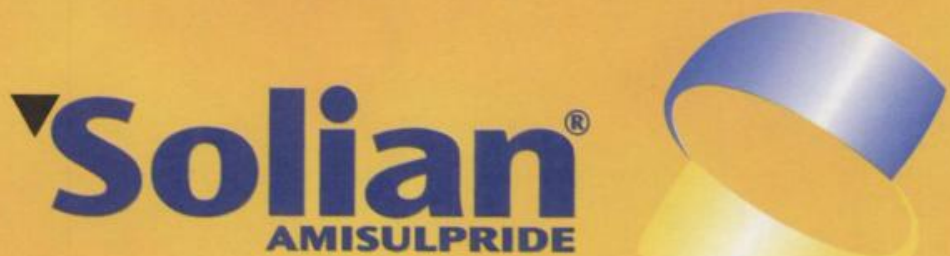

\section{Efficacy that patients can live with}

Prescribing Information - Solian 200 and Solian $50 \nabla$ Presentation: Solian 200mg tablets contain $200 \mathrm{mg}$ amisulpride and Solian $50 \mathrm{mg}$ tablets contain $50 \mathrm{mg}$ amisulpride. Indication: Acute and chronic schizophrenia in which positive and/or negative symptoms are prominent. Dosage: Acute psychotic episodes: $400-800 \mathrm{mg} /$ day, increasing up to $1200 \mathrm{mg} /$ day according to individual response (dose titration not required), in divided doses. Predominantly negative symptoms: $50-300 \mathrm{mg}$ once daily adjusted according to individual response. Elderly: administer with caution due to the risk of hypotension or sedation. Renal insufficiency: reduce dose and consider intermittent therapy. Hepatic insufficiency: no dosage adjustment necessary. Children: contraindicated in children under 15 vears (safety not established). Contraindications: Hypersensitivity; concomitant prolactin-dependent tumours e.g. pituitary gland prolactinaemias and breast cancer; phaeochromocytoma; children under 15 years; pregnancy; lactation; women of child-bearing potential unless using adequate contraception. Warning and Precautions: As with all neuroleptics, neuroleptic malignant syndrome may occur (discontinue Solian). Caution in patients with a history of epilepsy and Parkinson's disease. Interactions: Caution in

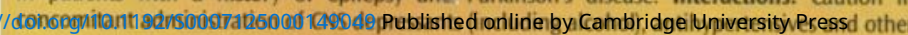

hypotensive medications, and dopamine agonists. Side Effects: Insomnia, anxiety, agitation. Less commonly somnolence and GI disorders. In common with other neuroleptics: Solian causes a reversible increase in plasma prolactin levels; Solian may also cause weight gain, acute dystonia, extrapyramidal symptoms, tardive dyskinesia, hypotension and bradycardia; rarely, allergic reactions, seizures and neuroleptic malignant syndrome have been reported. Basic NHS Cost: Blister packs of: $200 \mathrm{mg} \times 60$ tablets - $£ 60.00 ; 200 \mathrm{mg} \times 90$ tablets $-£ 90.00$; $50 \mathrm{mg} \times 60$ tablets £16.45; $50 \mathrm{mg} \times 90$ tablets - £24.69. Legal Category: POM. Product Licence Numbers: Solian 200 - PL 15819/0002, Solian 50 - PL 15819/0001, Product Licence Holder: Lorex Synthélabo UK and Ireland Ltd, Foundation Park, Roxborough Way, Maidenhead, Berks, SL6 3UD. References: 1. Freeman HL. Int Clin Psychopharmacol 1997;12(Suppl 2):S11-S17. 2. Moller HJ. 6th World Congress of Biological Psychiatry, Nice, France, June 22-27 1997. 3. Coukell AJ, Spencer CM, Benfield P. CNS Drugs (Adis) 1996 Sep 6 (3):237-256. 4. Solian SPC. Lorex Synthélabo. 5. Sertindole SPC. Lundbeck Ltd. 6. Clozapine SPC. Novartis. Date of preparation: October 1997. SOL 7b 


\section{AKATHISIA}

\section{TREMOR}

\section{DYSTONIA}

RIGIDITY

\section{Lundbeck}

Serdolect: ${ }^{2}$ Abbreviated Prescribing Information

Presentation: Tablets of $4 \mathrm{mg}, 12 \mathrm{mg}, 16 \mathrm{mg}$ or $20 \mathrm{mg}$ sertindole. Indications: Treatment of schizophrenia. Not for urgent relief of symptoms in acutely disturbed patients. Dosage and administration: Tablets should be taken orally once daily without regard for food. Adults. All patients should be started on $4 \mathrm{mg} /$ day. The dose should be increased by $4 \mathrm{mg}$ increments after $4-5$ days on each dose to the optimum daily maintenance dose range of $12-20 \mathrm{mg}$. The dose may be increased to a maximum of $24 \mathrm{mg}$. Retitration is necessary if dosing is suspended for more than one week. Children. Not recommended. Mild to moderote hepatic impoiment. Slower titration and lower maintenance dose. Elderly. Slower titration and lower maintenance doses may be required. Contra-indications: Known prolongation of QT interval or combined use of drugs known to prolong QT interval. Clinically significant cardiac disease or

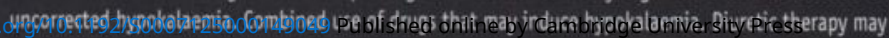

be initiated if required but a potassium-sparing agent must be used. Combined use of quinidine or systemic ketoconazole or itraconazole. Severe hepatic impairment. Hypersensitivity to Serdolect. Pregnancy and lactation: Safety during human pregnancy and lactation has not been established and Serdolect should not be used during pregnancy. Nursing mothers should not breastfeed if they are taking Serdolect. Precautions: Serdolect is not sedative, however, patients should be advised not to drive or operate machinery until their individual susceptibility is known. History of diabetes, seizures, Parkinson's disease. Symptoms of orthostatic hypotension may occur and blood pressure should be monitored during initial dose titration and in early maintenance phase. In common with other antipsychotic drugs, Serdolect lengthens the QT interval in some patients $(<1.7 \%$ of patients). Electrolyte imbalance or combined use of other drugs that inhibit Serdolect metabolism can increase the risk of occurrence of prolonged QT interval. An ECG should be performed prior to use with periodic ECG 

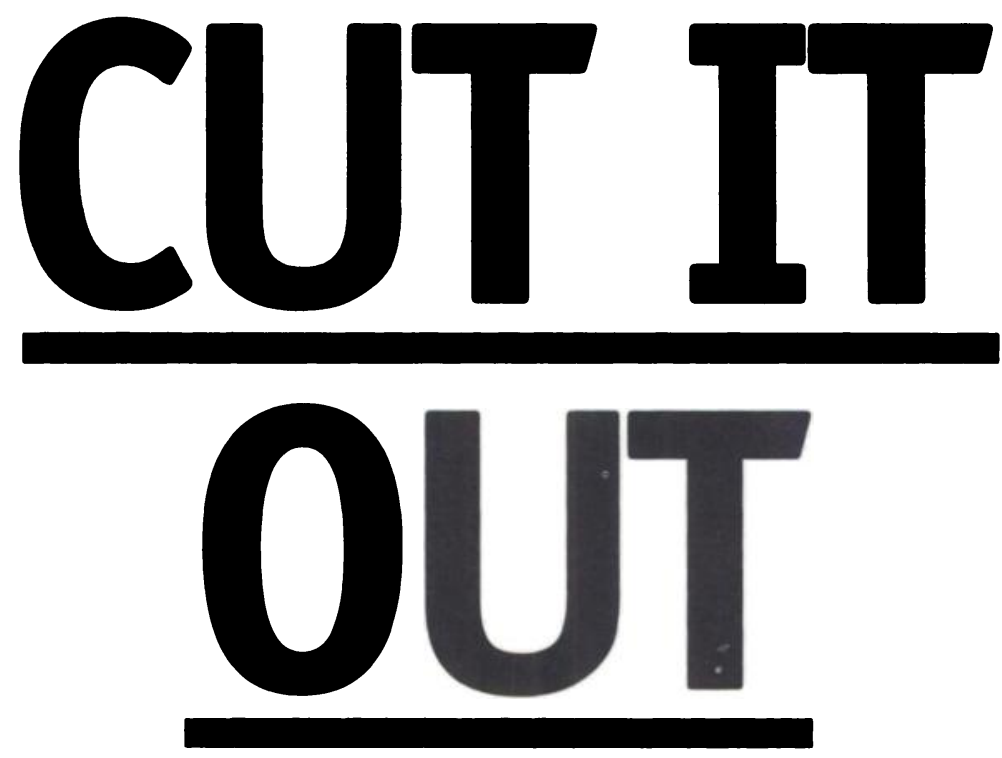

\section{A new window of opportunity}

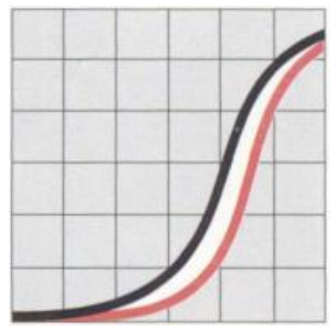

is opening in the treatment of schizophrenia, with the promise of substantial improvements to the quality of patients' lives.

Serdolect ${ }^{\oplus}$ is a novel limbicselective anti-psychotic.

Pre-clinical studies have shown that it inhibits the number of spontaneously active dopamine neurones in the mesolimbic ventral tegmental area without affecting dopamine neurones in the substantia nigra. Furthermore, it has been found to be more selective than certain other atypical drugs. ${ }^{1}$ This indicates that Serdolect $^{\circledR}$ may have a lower potential for producing extrapyramidal side-effects across the therapeutic ranje.

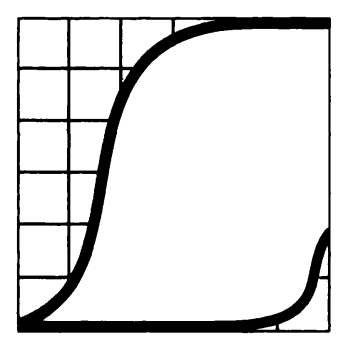

\section{Serdolect ${ }^{\oplus}$ opens the window of} opportunity for your patients

- Effective against positive and negative symptoms $\mathrm{s}^{2,3}$

- Placebo-level EPS at all doses tested ${ }^{2,3}$

- Sedation at placebo level ${ }^{4}$

- No clinically significant changes in haematological parameters ${ }^{4}$

- Mean serum prolactin levels maintained within normal limits"

- Once daily dosage

- One price for all routine maintenance doses

Thankfully, such a profile not only extends your choice, it also opens the window of opportunity for your patients.

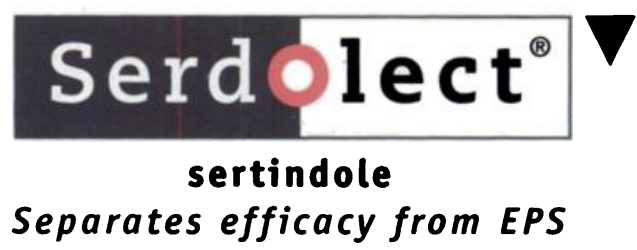

dopamine should not be used (may exacerbate hypotension). Cardiovascular monitoring recommended. Administration of activated charcoal and laxative should be considered. Package quantities and basic NHS price: $4 \mathrm{mg}$ tablets, $\mathrm{f} 36.63$ for 30 tablet pack. 12mg tablets, ₹102.55 for 28 tablet calendar pack. $16 \mathrm{mg}$ tablets, $\mathbf{f 1 0 2 . 5 5}$ for 28 tablet calendar pack. $20 \mathrm{mg}$ tablets, $£ 102.55$ for 28 tablet calendar pack. Legal category: POM. Product Licence numbers: 4mg: 13761/0001. 12mg: 13761/0003. 16mg: 13761/0004. 20mg: 13761/0005. Date of last review: November 1996. Further information is available on request from Lundbeck Limited, Sunningdale House, Caldecotte Lake Business Park, Caldecotte, Milton Keynes, MK7 8LF. Serdolect' is a registered trademark of H. Lundbeck A/S. References: 1. Arnt J et ol. Poster presented at the 34th ACNP Meeting, December 1995, Puerto Rico. 2. Zborowski J et al. Poster presented at 148th APA Meeting, May 1995, Miami, Florida. 3. Daniel DG et ol. J Psych: In Press. 4. Data on file, H. Lundbeck A/S. 

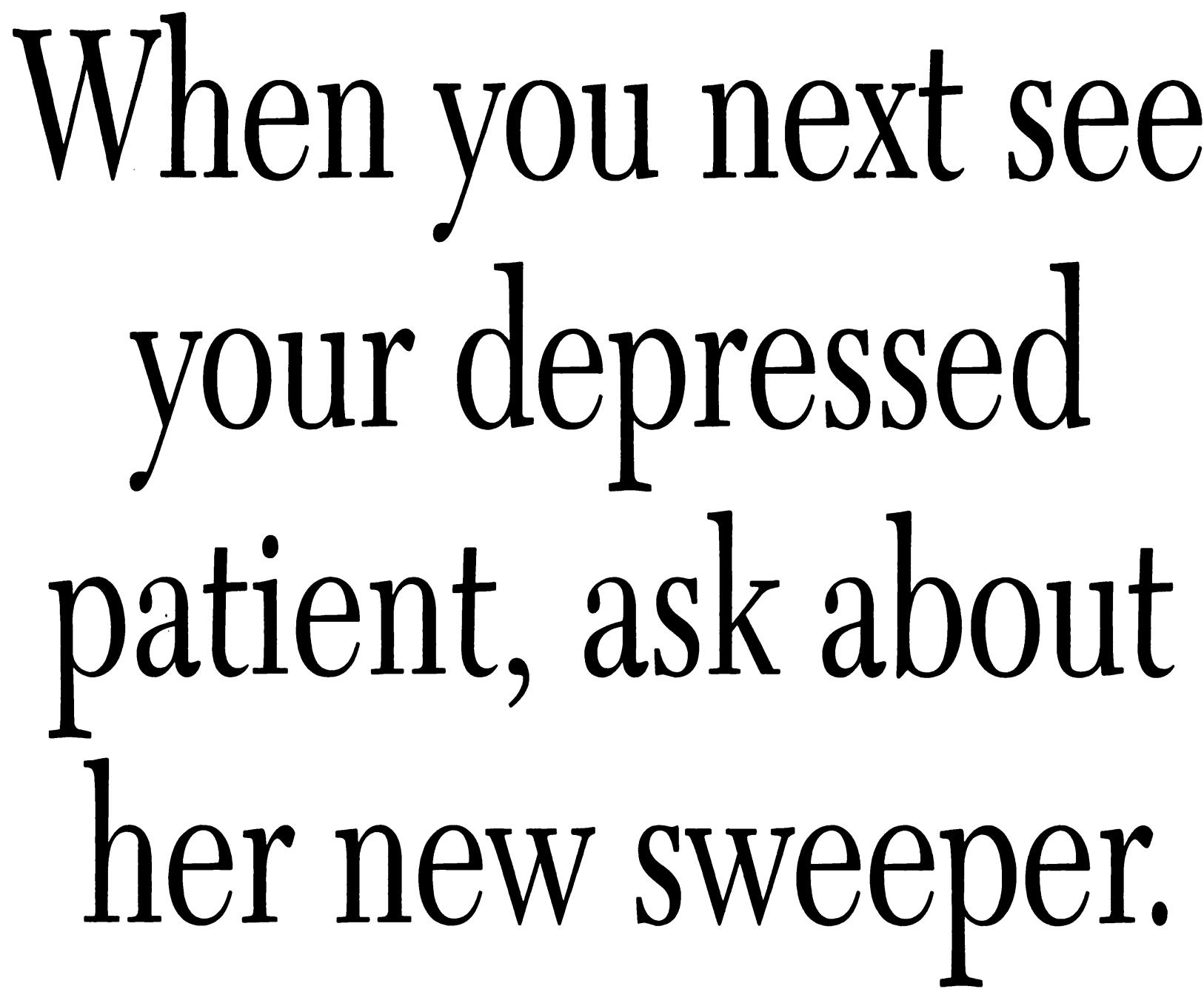

D epression. It's not a game, but it can be viewed in two halves. Most antidepressants play a valuable part in the first half they lift mood and relieve anxiety. But what of the second? Do they reduce fatigue, improve motivation and improve social functioning, so your patient can play a full part again, in the things they once enjoyed? Here's some information about new Edronax, you be the referee:

Edronax is a new selective NorAdrenaline Re-uptake Inhibitor (NARI). It not only lifts depressed mood,' but also significantly improves social interaction. ${ }^{2}$

These improvements in social functioning have been trial-proven by using the innovative SASS questionnaire (Social Adaptation Self-evaluation Scale). ${ }^{3}$
Edronax improves mood one week earlier than fluoxetine.' Additionally, when compared to fluoxetine, Edronax shows a significantly better outcome in terms of social functioning. ${ }^{2}$

Edronax helps restore patients' appreciation of friends, family, work and hobbies, and improves their self-perception.

Prescribe $4 \mathrm{mg}$ b.d. then make your usual assessments, to see the Edronax difference. The SASS questionnaire, which patients can complete in their own time, may also help.

For free copies of the SASS questionnaire, please telephone 01908603083.

And the next time you see your depressed patient, ask them how they performed, in both halves.

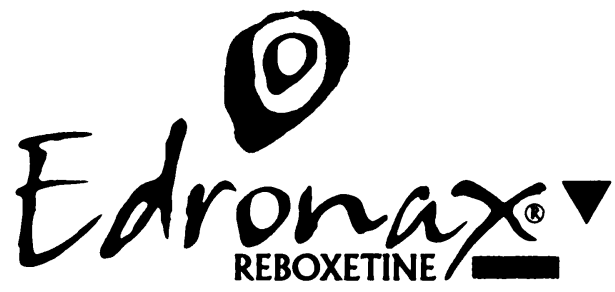

A NeW SELECTIVE NARI. LIFTS DEPRESSION. HeLPS RESTORE SOCIAL INTERACTION.

contraindicated in pregnancy and lactation. Ellects on abiity to dive and use mactines: Reboxetine is not sedative per se. However, as with all psychoactive drugs, caution patients about operating machinery and driving. Undesirable eflects: Adverse events occurring more frequently than placebo are: dry mouth, constipation, insomnia, paraesthesia, increased sweating, tachycardia, vertigo, urinary hesitancy/retention, impotence. Overdose: Monitor cardiac function and

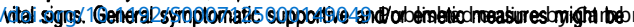
required. Package and NHS Price: Pack of 60 tablets in blisters $\$ 19.80$. Loget
Davy Avenue, Mition Keynes, MK5 8PH, UK. Marketing Authorisation Mumber. PL 00320216, Date of Preperation: October 1997. Roferences: 1. Montgomery SA. Joumal of Psychoophamacology 1997 (in press). 2. Dubini A. et al. European Neuropsychophamacol. 1997; 7 (Supol 1): S57-S70. 3. Bosc M. et al. European Neuropsychopharmacol. 1997; 7 (Suppl 1): S57-S70. Further information is available from Pharmacia \& Upjohn Limited, Davy Avenue, Knowlhill, Mitton gkelymes, EMAK5)8PHedHK. Telephone: 01908661101 . Edronax is a registered trademark. 


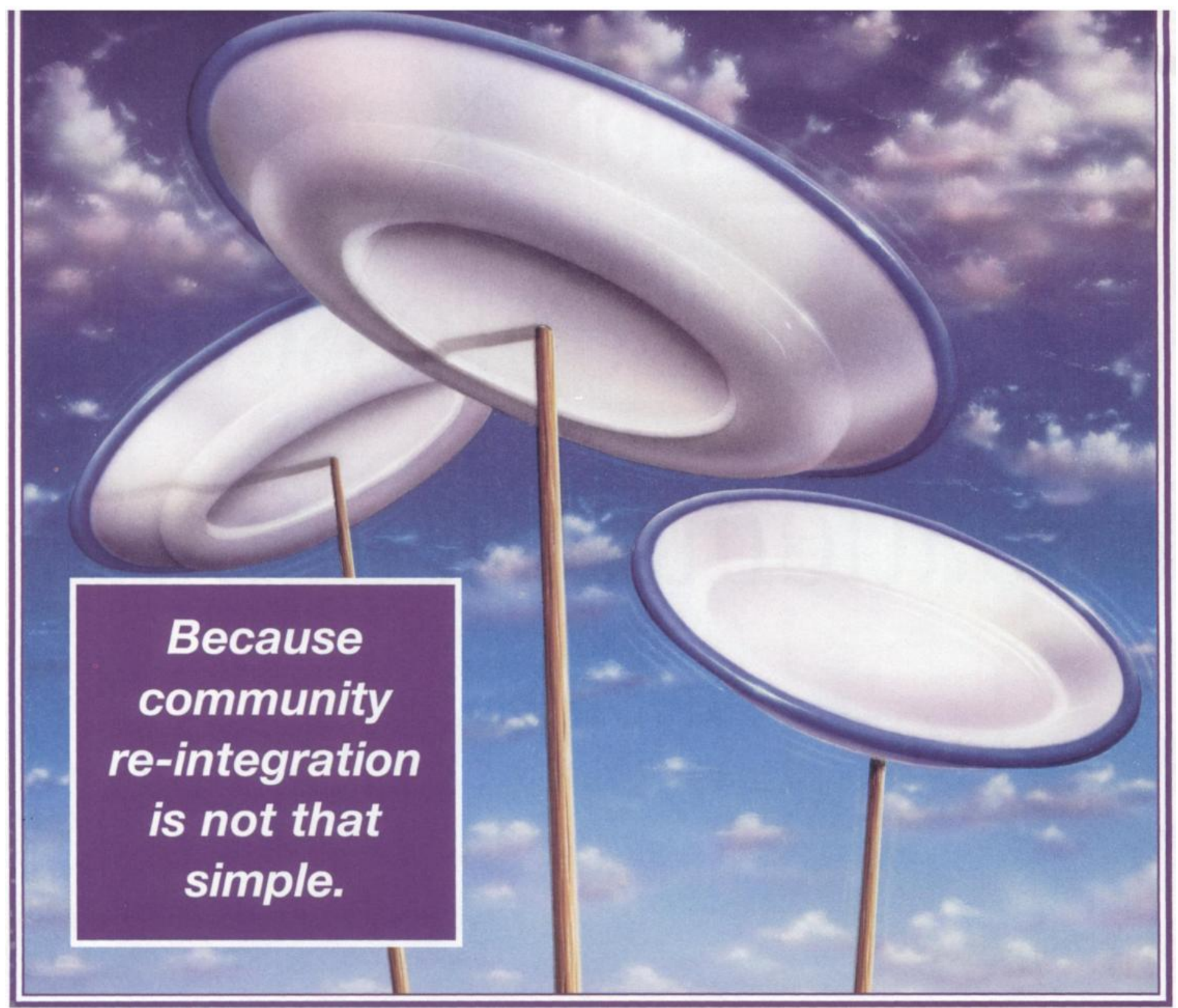

\section{ABbreVIATED PRESCRIBING INFORMATION:} Presentation: Coated tablets containing $5 \mathrm{mg}, 7.5 \mathrm{mg}$ or $10 \mathrm{mg}$ of olanzapine. The tablets also contain lactose. Uses: Schizophrenia, both as initial therapy and for maintenance of response. Further Information: In studies of patients with schizophrenia and associated depressive symptoms, mood score improved significantly more with olanzapine than with haloperidol. Pharmacodynamics: Olanzapine was associated with significantly greater improvements in both negative and positive schizophrenic symptoms than placebo or comparator in most studies. Dosage and Administration: $10 \mathrm{mg} /$ day orally, as a single dose without regard to meals. Dosage may subsequently be adjusted within the range of $5-20 \mathrm{mg}$ daily. An increase to a dose greater than the routine therapeutic dose of $10 \mathrm{mg} /$ day is recommended only after clinical assessment. Children: Not recommended under 18 years of age. The elderty: A lower starting dose (5mg/day) is not routinely indicated but should be considered when clinical factors warrant. Hepatic and/or renal impairment: A lower starting dose $(5 \mathrm{mg})$ may be considered. When more than one factor is present which might result in slower metabolism (female gender, elderly age. non-smoking status), consideration should be given to decreasing the starting dose. Dose escalation should be conservative in such patients. Contra-indications: Known hypersensitivity to any ingredient of the product. Known risk for narrow-angle glaucoma. Warnings and Special Precautions: Caution in patients with prostatic hypertrophy, or paralytic ileus and related conditions. Caution in patients with elevated ALT and/or AST, signs and symptoms of hepatic impairment, pre-existing conditions associated with limited hepatic functional reserve, and in patients who are being treated with potentially hepatotoxic drugs. As with other neuroleptic drugs, caution in patients with low leucocyte and/or neutrophil counts for any reason, a history of drug-induced bone marrow depression/toxicity, bone marrow depression caused by concomitant illness, radiation therapy or chemotherapy and in patients with hypereosinophilic conditions or with myeloproliferative disease. Thirty-two patients with clozapine-related neutropenia or agranulocytosis histories received olanzapine without decreases in baseline neutrophil counts. Although, in clinical trials, there were no reported cases of NMS in patients receiving olanzapine, if such an event occurs, or if there is unexplained high fever, all antipsychotic drugs, including olanzapine, must be discontinued. Caution in patients who have a history of seizures or have conditions associated with seizures. I signs or symptoms of tardive dyskinesia appear a dose reduction or drug discontinuation should be considered. Caution when taken in combination with other centrally acting drugs and alcohol. Olanzapine may antagonise the effects of direct and

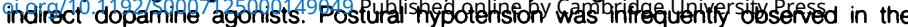

elderly. However, blood pressure should be measured periodically in patients over 65 years, as with other antipsychotics. As with other antipsychotics, caution when prescribed with drugs known to increase QTC interval, especially in the elderly. In clinical trials, olanzapine was not associated with a persistent increase in absolute QT intervals. Interactions: Metabolism may be induced by concomitant smoking or carbamazepine
therapy. Pregnancy and Lactation: Olanzapine had no teratogenic effects in

animals. Because human experience is limited olanzapine should be used in pregnancy only if the potential benefit justifies the potential risk to the foetus. Olanzapine was excreted in the milk of treated rats but it is not known if it is excreted in human milk. Patients should be advised not to breast feed an infant if they are taking olanzapine. Driving, etc: Because olanzapine may cause somnolence, patients should be cautioned about operating hazardous machinery, including motor vehicles. Undesirable Effects: The only frequent $(>10 \%)$ undesirable effects associated with the use of olanzapine in clinical trials were somnolence and weight gain. Occasional undesirable effects included dizziness, increased appetite, peripheral oedema, orthostatic hypotension, and mild, transient anticholinergic effects, including constipation and dry mouth. Transient, asymptomatic elevations of hepatic transaminases, ALT, AST have been seen occasionally. Olanzapine-treated patients had a lower incidence of parkinsonism, akathisia and dystonia in trials compared with titrated doses of haloperidol. Photosensitivity reaction or high creatinine phosphokinase were reported rarely. Plasma prolactin levels were sometimes elevated, but associated clinical manifestations were rare. Asymptomatic haematological variations were occasionally seen in trials. For further information see summary of product characteristics. Legal Category: POM. Marketing Authorisation Numbers: EU/1/96/022/004 EU/1/96/022/006 EU/1/96/022/008 EU/1/96/022/009 EU/1/96/022/010. Basic NHS Cost: $£ 52.73$ per pack of $28 \times 5 \mathrm{mg}$ tablets. $£ 105.47$ per pack of $28 \times 10 \mathrm{mg}$ tablets. $£ 158.20$ perpack of $56 \times 7.5 \mathrm{mg}$ tablets. $£ 210.93$ per pack of $56 \times 10 \mathrm{mg}$ tablets. Date of Preparation or Last Review: April 1997. Full Prescribing Information is Available From: Eli Lilly and Company Limited, Dextra Court, Chapel Hill, Basingstoke Hampshire RG21 5SY. Telephone: Basingstoke (01256) 315000

'ZYPREXA' is a Lilly trademark.

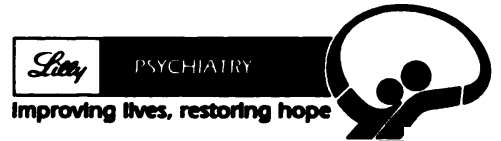




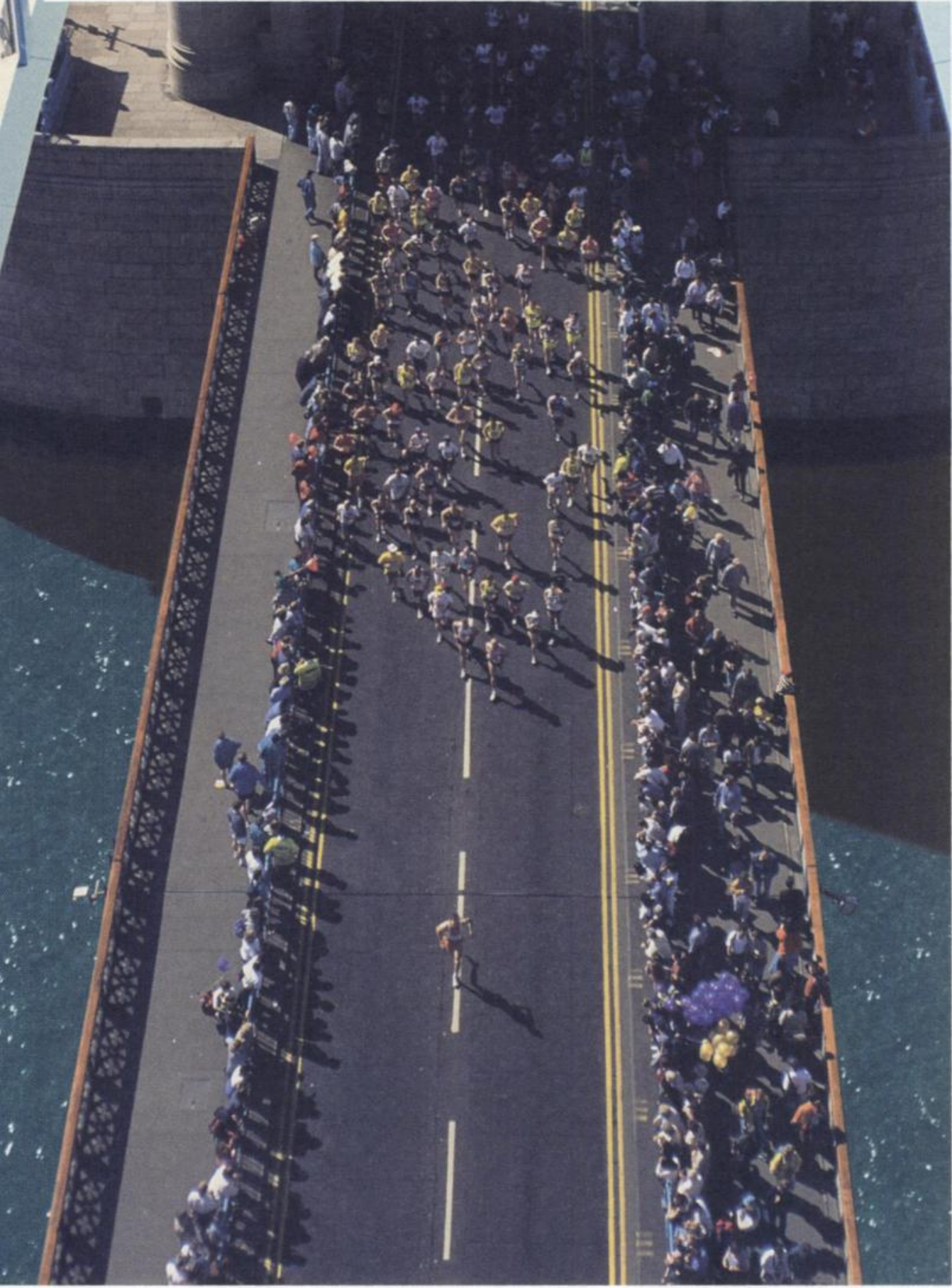

\author{
ASSOCIATED \\ ANXIETY
}

Prozac has a proven

record of efficacy in

depression, ${ }^{1,2,3}$ with a

confirmed indication

in depression with or

without associated

anxiety symptoms. ${ }^{4}$

A possible reason why

Prozac has earned its

status around the world.

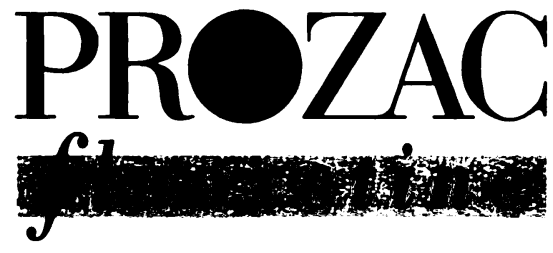

\title{
The World's No.1 prescribed antidepressant brand.'
}

'PROZAC' ABBREVIATED PRESCRIBING INFORMATION (FLUOXETINE HYDROCHLORIDE) Presentation Capsules containing $20 \mathrm{mg}$ or $60 \mathrm{mg}$ fluoxetine, as hydrochloride, per $5 \mathrm{ml}$ syrup. LSF Depression TREATMENT OF THE SIMPTOMS OH DEPRFSSIN' ILLNESS, WITH OR WITHOCT ASSOCIATED A IXIETY SYMPTOMS Obsessive-compulsive disorder. Bulimia nerwosa: For the reduction of binge-eating and purging activity. Dosage and Administration (For full information, see data sheet.) For oral administration to adults only. Depression, with or without associated anxiery symptoms - aduls and the elderly: A dose of $20 \mathrm{mg} / \mathrm{day}$ is recommended. absessin compulsin asorder. 20mg/day to 60mg/ay. A dose of $20 \mathrm{mg}$ day is recommended as the initial dose. Bulimia - adults and the recommended. Because of the long elimination half-lives of the parent drug (1.3 days atter acule administration: may be prolonged to 4.6 days after chronic administration) and its major metabolite (average 9.3 days), active drug substance will persist in the body for several weeks after dosing is stopped. The capsule and liquid dosage forms are bioequivalent. Children: No recommended. Patients with renal andlor hepatic dysfuncion: See 'Contra-indications' and 'Precautions' sections. Contraindications Hypersensitivity to fluoxetine. Prozac should not be administered to patients with severe renal failure IGFR $<10 \mathrm{ml} / \mathrm{min})$. Usage in nursing mothers: Prozac should not be prescribed to nursing mothers. Monoamine oxidase inhibitor At prescribed lo nussing mothers. Moncam doxidase inhibions: A

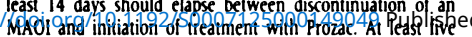
weeks should elapse between discontinuation of Prozac and reactions of therapy with an MAOI. Scrious, sometimes talal catreme outution.tity and mental status changes that incude reported with concomitant use or when fluoxetine had been recently discontinued and an MAOI started. Some cases presented with features resembling neuroleptic malignant syndrome. Warnines Rosh and allergic reactions: Angioneurotic oedema, unicaria and other allergic reactions have been reponed. Upon appearance of rash or of other allergic reponed. Upon appearance of rash, of of other allergic phom aetiology cannot be Prone Precac should be avoided be disso there is no saler aliemative. Precautions Prozac should be discontinued in any patient who develops seizures. Prozac should be aveded in patients with unstable epilepsy. patients with controlled epilepsy should be carefully monitored. There have been rare repons of prolonged seizures in patients on fluoxetine receiving ECT treatment. A lower dose of Prozac, eq, alternate day dosing is recommended in patients with significant hepatic dysfunction or mild to moderate renal failure (GFR $10.50 \mathrm{~m} / \mathrm{min}$ ). Caution is advisable when Prozac is used in patients with acute cardiac disease. Prozac may cause weight loss which may be undesirable in underweight depressed patients. In diabetics, fluoxetine may alter glycaemic control. There have been reports of abnormal bleeding in several patients, but causal relationship to fuoxetine and dinical importance are undear. Drug interactions:

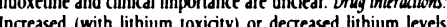
oncreased (with lithium toxicity or decreased lithium levels Because fluoxetine's metabolism involves the hepatic
Cytoctrome P4501106 isocizyme system, concom lant therapy have a narrow herapeutic index

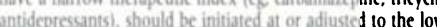
end of their dose range. Greater than 2-fold increases of previously stable plasma levels of cyclic antidepressants have been observed when Prozac has been administered in combination. Agitation, restlessness and gastro-intestina symptoms have been reponed in a small number of patients receiving fuoxecine in combination with iryptophan Patients on suble phenyin in doses have developed elevated plasma clasma concentrations and dinical phenyloin toxicity after starting efere lass dishena, fever, nusse, dianthoed, dry mouth, appetile loss, dyspepsia, voming rarely abnormal LFs, headache. nervousness, insomnia, drowsiness, anxiety, tremor, dizziness latigue. decreased libido, seizures. hypomania or mania. dyskinesia, movement disorders, neuroleptic malignan syndrome-like events, pharyngitis, dyspnoea, pulmonary events (including inflammatory processes and/or fibrosis), rash urticaria, vasculitis, excessive sweating, arthralgia, myalgia serum sickness. anaphylactoid reactions, hair loss, sexua dysfunction. The following have been reponted in association with fluoxetine but no causal relationship has been established: aplastic anaemia, cerebral vascular accident confusion ecchymoses, eosinophilic pneumonia, pastro-intestina haemorthage hyperprolacinaemia immune-related haemolyic anaemia pancreatitis,

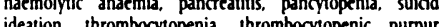
vagina beeding arer drug withdral and violent purpura
Hyponatraemia (induding serum sodium below $110 \mathrm{mmol} /$ ) has been rarely reponed. This appears to be reversible upon discontinuation. Overdosage on the evidence available fluoxetine has a wide margin of salety in overdose. Since introduction, repons of death. attributed to overdosage of fluoxetine alone, have been extremely rare. One patient who reportedly took $3000 \mathrm{mg}$ of fuoxetine experienced 2 grand mal seizures that remitted sponianeously. Prodect Bxic NHS Cost 2077 per pad of 30 capsules 20 mo 667.85 per pack o 98 capsuls 22 pack. Per pact Rever Rextra Court. Chapel Hill, Basingstoke, Hampshire, RG21 5SY. Telephone: Basingstoke (01256) 52011

Reierences:I. Data on file, Dista Products L.d. 2. Tignol J. J Clin Psychopharm 1993; 13 (6, suppl. 2): 185.22S. 3. Bennie EH Mullin JM. Martindale JJ. J Clin Psychiatry 1995; 36: 229-237. 4. Prozac Data Sheet 24M.

Date of preparation: May 1997

PZ 906

Laxy

Improving lives, restoring hope 


\section{Books from Gaskell}

\section{The Psychotherapy of Psychosis}

\author{
Edited by Chris Mace and Frank Margison
}

\section{This book provides an unusually} comprehensive survey of the current state and prospects of psychological methods of treatment for people with schizophrenia and other psychotic illnesses. It will be an invaluable resource for mental health professionals and clinical managers involved in their care, and essential reading for psychiatrists at all levels of experience.

The three traditions of psychotherapy and integrated approaches are covered. Recent research in the process and outcome of psychotherapy is reviewed and summarised. Clear advice is also given on treatment techniques and settings with reference to national policies.

As with other titles in the series, there is frequent use of boxes, tables and figures to set out important points and key information.

1997, 296pp, ISBN 190124204 8, £25.00

Gaskell books are available from the Publications Department, Royal College of Psychiatrists,

17 Belgrave Square, London SW1X 8PG

(Tel. +44(0)171 235 2351, extension 146). The latest information on College publications is available on the INTERNET at: http://www.demon.co.uk/rcpsych/

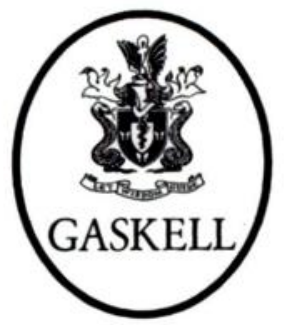

\section{RISPERDAL $^{\mathrm{M}}$ ABBREVIATED PRESCRIBING INFORMATION}

Please refer to Summary of Product Characteristics before prescribing Risperdal (risperidone). USES The treatment of acute and chronic schizophrenia, and other psychotic conditions, in which positive and/or negative symptoms are prominent. Risperdal also alleviates affective symptoms associated with schizophrenia. DOSAGE Where medically appropriate, gradual discontinuation of previous antipsychotic treatment while Risperdal therapy is initiated is recommended. Where medically appropriate, when switching patients from depot antipsychotics, consider initiating Risperdal therapy in place of the next scheduled injection. The need for continuing existing antiparkinson medication should be re-evaluated periodically. Adults: Risperdal may be given once or twice daily. All patients, whether acute or chronic, should start with $2 \mathrm{mg} /$ day. This should be increased to $4 \mathrm{mg} /$ day on the second day and $6 \mathrm{mg} /$ day on the third day. However, some patients such as first-episode psychotic patients may benefit from a slower rate of titration. From then on the dosage can be maintained unchanged, or further individualised if needed. The usual effective dosage is 4 to $8 \mathrm{mg} /$ day although in some patients an optimal response may be obtained at lower doses. Doses above 10 mg/day may increase the risk of extrapyramidal symptoms and should only be used if the benefit is considered to outweigh the risk. Doses above $16 \mathrm{mg} /$ day should not be used. Elderly, renal and liver disease: A starting dose of $0.5 \mathrm{mg}$ bd is recommended. This can be individually adjusted with $0.5 \mathrm{mg}$ bd increments to 1 to $2 \mathrm{mg}$ bd. Risperdal is well tolerated by the elderly. Use with caution in patients with renal and liver disease. Not recommended in children aged less than 15 years. CONTRANDICATIONS, WARNINGS, ETC. Contraindications: Known hypersensitivity to Risperdal. Precautions: Orthostatic hypotension can occur (alpha-blocking effect). Use with caution in patients with known cardiovascular disease. Consider dose reduction if hypotension occurs. For further sedation, give an additional drug (such as a benzodiazepine) rather than increasing the dose of Risperdal. Drugs with dopamine antagonistic properties have been associated with tardive dyskinesia. If signs and symptoms of tardive dyskinesia appear, the discontinuation of all antipsychotic drugs should be considered. Caution should be exercised when treating patients with Parkinson's disease or epilepsy. Patients should be advised of the potential for weight gain. Risperdal may interfere with activities requiring mental alertness. Patients should be advised not to drive or operate machinery until their individual susceptibility is known. Pregnancy and lactation: Use during pregnancy only if the benefits outweigh the risks. Women receiving Risperdal should not breast feed. Interactions: Use with caution in combination with other centrally acting drugs. Risperdal may antagonise the effect of levodopa and other dopamine agonists. On initiation of carbamazepine or other hepatic enzyme-inducing drugs, the dosage of Risperdal should be re-evaluated and increased if necessary. On discontinuation of such drugs, the dosage of Risperdal should be re-evaluated and decreased if necessary. Side effects: Risperdal is generally well tolerated and in many instances it has been difficult to differentiate adverse events from symptoms of the underlying disease. Common adverse events include: insomnia, agitation, anxiety, headache. Less common adverse events include: somnolence, fatigue, dizziness, impaired concentration, constipation, dyspepsia, nausea/vomiting, abdominal pain, blurred vision, priapism, erectile dysfunction, ejaculatory dysfunction, orgasmic dysfunction, urinary incontinence, rhinitis, rash and other allergic reactions. The incidence and severity of extrapyramidal symptoms are significantly less than with haloperidol. However, the following may occur: tremor, rigidity, hypersalivation, bradykinesia, akathisia, acute dystonia. If acute, these symptoms are usually mild and reversible upon dose reduction and/or administration of antiparkinson medication. Rare cases of Neuroleptic Malignant Syndrome have been reported. In such an event, all antipsychotic drugs should be discontinued. Occasionally, orthostatic dizziness, hypotension (including orthostatic), tachycardia (including reflex) and hypertension have been observed. An increase in plasma prolactin concentration can occur which may be associated with galactorrhoea, gynaecomastia and disturbances of the menstrual cycle. Oedema and increased hepatic enzyme levels have been observed. A mild fall in neutrophil and/or thrombocyte count has been reported. Rare cases of water intoxication with hyponatraemia, tardive dyskinesia, body temperature dysregulation and seizures have been reported. Overdosage: Reported signs and symptoms include drowsiness and sedation, tachycardia and hypotension, and extrapyramidal symptoms. A prolonged QT interval was reported in a patient with concomitant hypokalaemia who had ingested $360 \mathrm{mg}$. Establish and maintain a clear airway, and ensure adequate oxygenation and ventilation. Gastric lavage and activated charcoal plus a laxative should be considered. Commence cardiovascular monitoring immediately, including continuous electrocardiographic monitoring to detect possible arrhythmias. There is no specific antidote, so institute appropriate supportive measures. Treat hypotension and circulatory collapse with appropriate measures. In case of severe extrapyramidal symptoms, give anticholinergic medication. Continue close medical supervision and monitoring until the patient recovers. PHARMACEUTICAL PRECAUTIONS Tablets: Store below $30^{\circ} \mathrm{C}$. Liquid: Store between $15^{\circ} \mathrm{C}$ and $30^{\circ} \mathrm{C}$ and protect from freezing. LEGAL CATEGORY POM. PRESENTATIONS, PACK SIZES, PRODUCT LICENCE NUMBERS \& BASIC NHS COSTS White, oblong tablets containing $1 \mathrm{mg}$ risperidone in packs of 20. PL $0242 / 0186 £ 13.45$. Pale orange, oblong tablets containing $2 \mathrm{mg}$ risperidone in packs of 60. PL 0242/0187 $£ 79.56$. Yellow, oblong tablets containing $3 \mathrm{mg}$ risperidone in packs of 60. PL $0242 / 0188 £ 117.00$. Green, oblong tablets containing $4 \mathrm{mg}$ risperidone in packs of 60. PL $0242 / 0189 \mathrm{f154.44}$. Starter packs containing 6 Risperdal $1 \mathrm{mg}$ tablets are also available $£ 4.15$. Clear, colourless solution containing $1 \mathrm{mg}$ risperidone per $\mathrm{ml}$ in bottles containing $100 \mathrm{ml}$. PL $0242 / 0199 £ 65.00$. FURTHER INFORMATION IS AVAILABLE FROM THE PRODUCT LICENCE HOLDER: Janssen-Cilag Ltd, Saunderton, High Wycombe, Buckinghamshire HP14 4HJ.

Date of preparation: April 1997

- Janssen-Cilag Led

n trademark

801116 


\section{Patient with schizophrenia exercises}

\section{self esteem by going downhill}

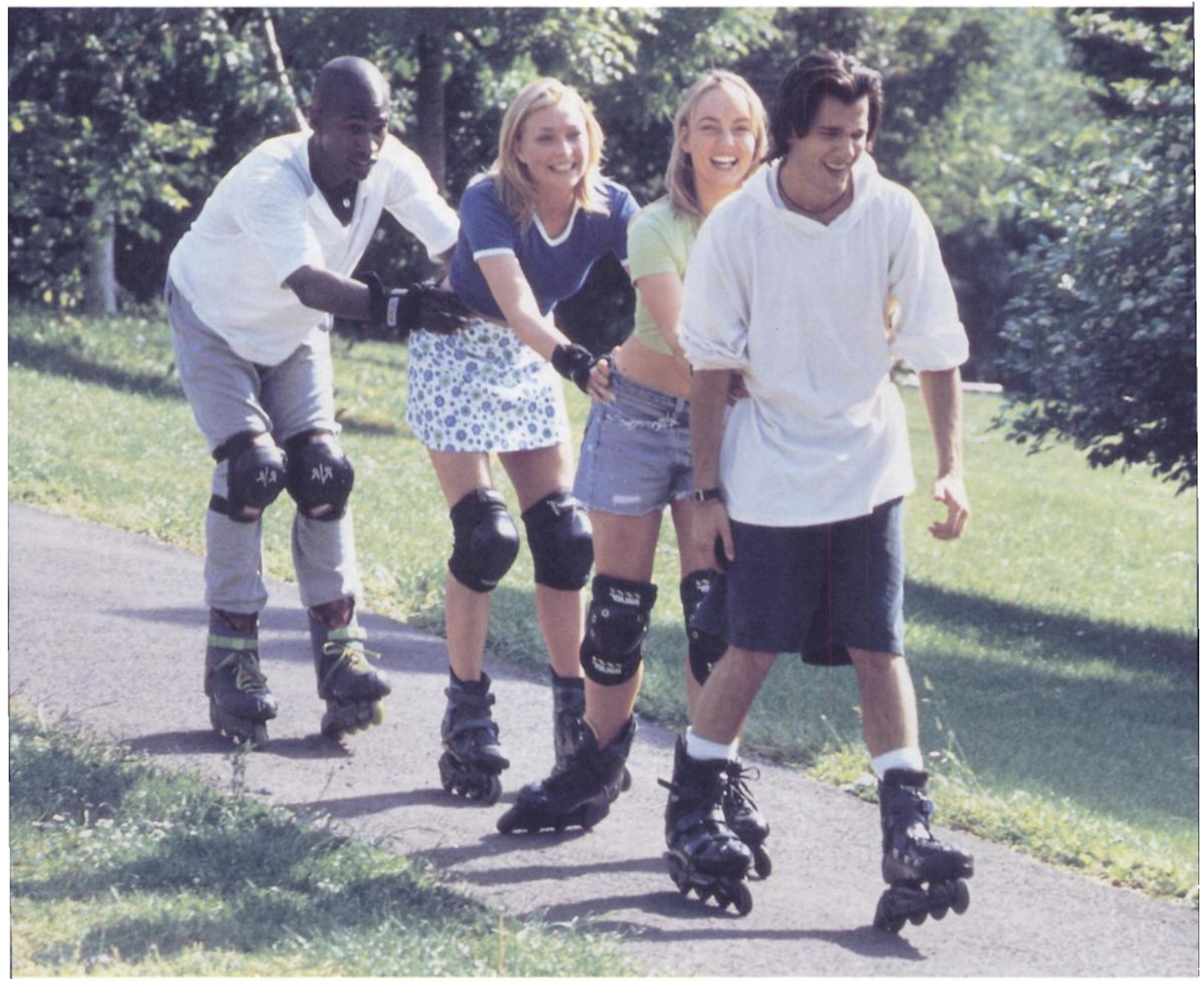

The SDA effect of Risperdal can mean a huge difference to the lives of patients with schizophrenia.

Because SDA is the action of Serotonin and Dopamine Antagonism in a single drug. In positive and negative symptoms. In first episode and acute presentations, and in chronic patients. Risperdal continues to provide this SDA effect to give high efficacy, with low levels of extrapyramidal side-effects, to more and more patients.
Helping them keep out of hospitals while enhancing their appreciation of, and participation in, community and family life.

The word is on the street.

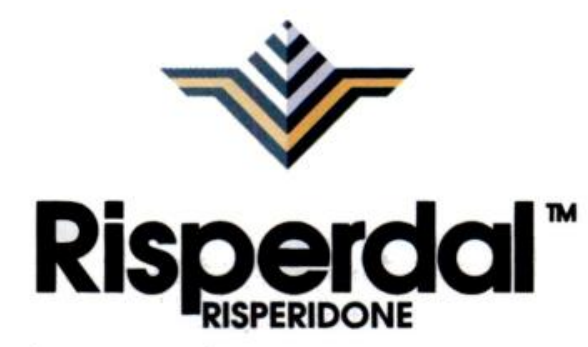

A routine route out 


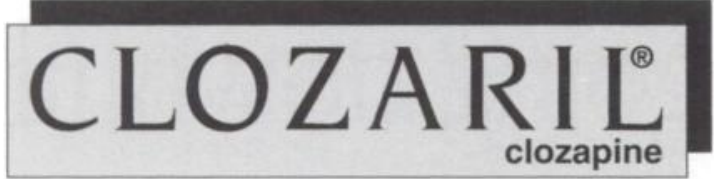

CLOZARIL ABBREVIATED PRESCRIBING INFORMATION. The use of CLOZARIL is restricted to patients registered with the CLOZARIL Patient Monitoring Service. Indication Treatmentresistant schizophrenia (patients non-responsive to, or intolerant of, conventional neuroleptics). Presentations $25 \mathrm{mg}$ and $100 \mathrm{mg}$ clozapine tablets. Dosage and Administration Initiation must be in hospital inpatients and is restricted to patients with normal white blood cell and differential counts. Initially, $12.5 \mathrm{mg}$ once or twice on the first day, followed by one or two $25 \mathrm{mg}$ tablets on the second day. Increase dose slowly, by increments to reach a therapeutic dose within the range of $200-450 \mathrm{mg}$ daily (see data sheet). The total daily dose should be divided and a larger portion of the dose may be given at night. Once control is achieved a maintenance dose of 150 to $300 \mathrm{mg}$ daily may suffice. At daily doses not exceeding $200 \mathrm{mg}$, a single administration in the evening may be appropriate. Exceptionally, doses up to $900 \mathrm{mg}$ daily may be used. Patients with a history of epilepsy should be closely monitored during CLOZARIL therapy since dose-related convulsions have been reported. Patients with a history of seizures, as well as those suffering from cardiovascular, renal or hepatic disorders, together with the elderly need lower doses $(12.5 \mathrm{mg}$ given once on the first day) and more gradual titration. Contra-Indications Allergy to any constituents of the formulation. History of druginduced neutropenia/agranulocytosis, myeloproliferative disorders, uncontrolled epilepsy, alcoholic and toxic psychoses, drug intoxication, comatose conditions, circulatory collapse and/or CNS depression of any cause, severe renal or cardiac failure, active liver disease, progressive liver disease or hepatic failure. Warning CLOZARIL can cause agranulocytosis. A fatality rate of up to $l$ in 300 has been estimated when CLOZARIL was used prior to recognition of this risk. Since that time strict haematological monitoring of patients has been demonstrated to be effective in markedly reducing the risk of fatality. Therefore, because of this risk its use is limited to treatment-resistant schizophrenic patients:- 1 . who have normal leucocyte findings and 2 . in whom regular leucocyte counts can be performed weekly during the first 18 weeks and at least every two weeks thereafter for the first year of therapy. After one year's treatment, monitoring may be changed to four weekly intervals in patients with stable neutrophil counts. Monitoring must continue throughout treatment and for four weeks after complete discontinuation of CLOZARIL. Patients must be under specialist supervision and CLOZARIL supply is restricted to pharmacies registered with the CLOZARIL Patient Monitoring Service. Prescribing physicians must register themselves, their patients and a nominated pharmacist with the CLOZARIL Patient Monitoring Service. This service provides for the required leucocyte counts as well as a drug supply audit so that CLOZARIL treatment is promptly withdrawn from any patient who develops abnormal leucocyte findings. Each time CLOZARIL is prescribed, patients should be reminded to contact the treating physician immediately if any kind of infection begins to develop, especially any flu-like symptoms. Precautions CLOZARIL can cause agranulocytosis. Perform pretreatment white blood cell count and differential count to ensure only patients with normal findings receive CLOZARIL. Monitor white blood cell count weekly for the first 18 weeks and at least two-weekly for the first year of therapy. After one year's treatment, monitoring may change to four weekly intervals in patients with stable neutrophil counts. Monitoring must continue throughout treatment and for four weeks after complete discontinuation. If signs or symptoms of infection develop an immediate differential count is necessary. If the white blood count falls below $3.0 \times 10^{9} / \mathrm{L}$ and/or the absolute neutrophil count drops below $1.5 \times 10^{9} / \mathrm{L}$, withdraw CLOZARIL immediately and monitor the patient closely, paying particular attention to symptoms suggestive of infection. Re-evaluate any patient developing an infection, or when a routine white blood count is between 3.0 and $3.5 \times 10^{9} / \mathrm{L}$ and/or a neutrophil count between 1.5 and $2.0 \times 10^{9} / \mathrm{L}$, with a view to discontinuing CLOZARIL. Any further fall in white blood/neutrophil count below $1.0 \times 10^{9} / \mathrm{L}$ and/or $0.5 \times$ $10^{9} / \mathrm{L}$ respectively, after drug withdrawal requires immediate specialised care, where protective isolation and administration of GMCSF or G-CSF and broad spectrum antibiotics may be indicated. Colony stimulating factor therapy should be discontinued when the neutrophil count returns above $1.0 \times 10^{9} / \mathrm{L}$. CLOZARIL lowers the seizure threshold. Orthostatic hypotension can occur therefore close medical supervision is required during initial dose titration. Patients affected by the sedative action of CLOZARIL should not drive or operate machinery, administer with caution to patients who participate in activities requiring complete mental alertness. Monitor hepatic function regularly in liver disease. Investigate any signs of liver disease immediately with a view to drug discontinuation. Resume only if LFTs return to normal, then closely monitor patient. Use with care in prostatic enlargement, narrow-angle glaucoma and paralytic ileus. Patients with fever should be carefully evaluated to rule out the possibility of an underlying infection or the development of agranulocytosis. Avoid immobilisation of patients due to increased risk of thromboembolism. Do not give CLOZARIL with other drugs with a substantial potential to depress bone marrow function. CLOZARIL may enhance the effects of alcohol, MAO inhibitors, CNS depressants and drugs with anticholinergic, hypotensive or respiratory depressant effects. Caution is advised when CLOZARIL therapy is initiated in patients who are receiving (or have recently received) a benzodiazepine or any other psychotropic drug as these patients may have an increased risk of circulatory collapse, which, on rare occasions, can be profound and may lead to cardiac and/or respiratory arrest. Caution is advised with concomitant administration of therapeutic agents which are highly bound to plasma proteins. Clozapine binds to and is partially metabolised by the isoenzymes cytochrome P450 $1 \mathrm{~A} 2$ and P450 2D6. Caution is advised with drugs which posses affinity for these isoenzymes. Concomitant cimetidine and high dose CLOZARIL was associated with increased plasma clozapine levels and the occurrence of adverse effects. Concomitant fluoxetine and fluvoxamine have been associated with elevated clozapine levels. Discontinuation of concomitant carbamazepine resulted in increased clozapine levels. Phenytoin decreases clozapine levels resulting in reduced effectiveness of CLOZARIL. No clinically relevant interactions have been noted with antidepressants, phenothiazines and type lc antiarrhythmics, to date. Concomitant use of lithium or other CNS-active agents may increase the risk of neuroleptic malignant syndrome. The hypertensive effect of adrenaline and its derivatives may be reversed by CLOZARIL. Do not use in pregnant or nursing women. Use adequate contraceptive measures in women of child bearing potential. Side-Effects Neutropenia leading to agranulocytosis (See Warning and Precautions) Rare reports of leucocytosis including eosinophilia. Isolated cases of leukaemia and thrombocytopenia have been reported but there is no evidence to suggest a causal relationship with the drug. Most commonly fatigue, drowsiness, sedation. Dizziness or headache may also occur. CLOZARIL lowers the seizure threshold and may cause EEG changes and delirium. Myoclonic jerks or convulsions may be precipitated in individuals who have epileptogenic potential but no previous history of epilepsy. Rarely it may cause confusion, restlessness, agitation and delirium. Extrapyramidal symptoms are limited mainly to tremor, akathisia and rigidity. Tardive dyskinesia reported very rarely. Neuroleptic malignant syndrome has been reported. Transient autonomic effects eg dry mouth, disturbances of accommodation and disturbances in sweating and temperature regulation. Hypersalivation Tachycardia and postural hypotension, with or without syncope, and less commonly hypertension may occur. In rare cases profound circulatory collapse has occurred. ECG changes, arrhythmias, pericarditis and myocarditis (with or without eosinophilia) have been reported, some of which have been fatal. Rare reports of thromboembolism. Isolated cases of respiratory depression or arrest, with or without circulatory collapse. Rarely aspiration may occur in patients presenting with dysphagia or as a consequence of acute overdosage. Nausea, vomiting and usually mild constipation have been reported. Occasionally obstipation and paralytic ileus have occurred. Asymptomatic elevations in liver enzymes occur commonly and usually resolve. Rarely hepatitis and cholestatic jaundice may occur. Very rarely fulminant hepatic necrosis reported. Discontinue CLOZARIL if jaundice develops. Rare cases of acute pancreatitis have been reported. Both urinary incontinence and retention and priapism have been reported. Isolated cases of interstitial nephritis have occurred. Benign hyperthermia may occur and isolated reports of skin reactions have been received. Rarely hyperglycaemia has been reported. Rarely increases in CPK values have occurred. With prolonged treatment considerable weight gain has been observed. Sudden unexplained deaths have been reported in patients receiving CLOZARIL. Package Quantities and Price Community pharmacies only $28 \times 25 \mathrm{mg}$ tablets: E12.52 (Basic NHS) $28 \times 100 \mathrm{mg}$ tablets: £50.05 (Basic NHS) Hospital pharmacies only $84 \times 25 \mathrm{mg}$ tablets: $\mathfrak{E} 37.54$ (Basic NHS) $84 \times 100 \mathrm{mg}$ tablets: 1150.15 (Basic NHS) Supply of CLOZARIL is restricted to pharmacies registered with the CLOZARIL Patient Monitoring Service. Product Licence Numbers $25 \mathrm{mg}$ tablets: PL 0101/0228 $100 \mathrm{mg}$ tablets: PL 0101/0229 Legal Category: POM. CLOZARIL is a registered Trade Mark. Date of preparation, August 1997. Full prescribing information, including Product Data Sheet is available from Novartis Pharmaceuticals UK Ltd. Trading as: SANDOZ PHARMACEUTICALS, Frimley Business Park, Frimley, Camberley, Surrey, GU16 5SG. 
As the list of antipsychotic agents grows... ...isn't it time to consider one in a different class?

\section{CLOZAR R L L \\ Proven efficacy in treatment resistant schizophrenia}




\section{THE CONSTANT CURRENT SERIES 5B E.C.T. APPARATUS}

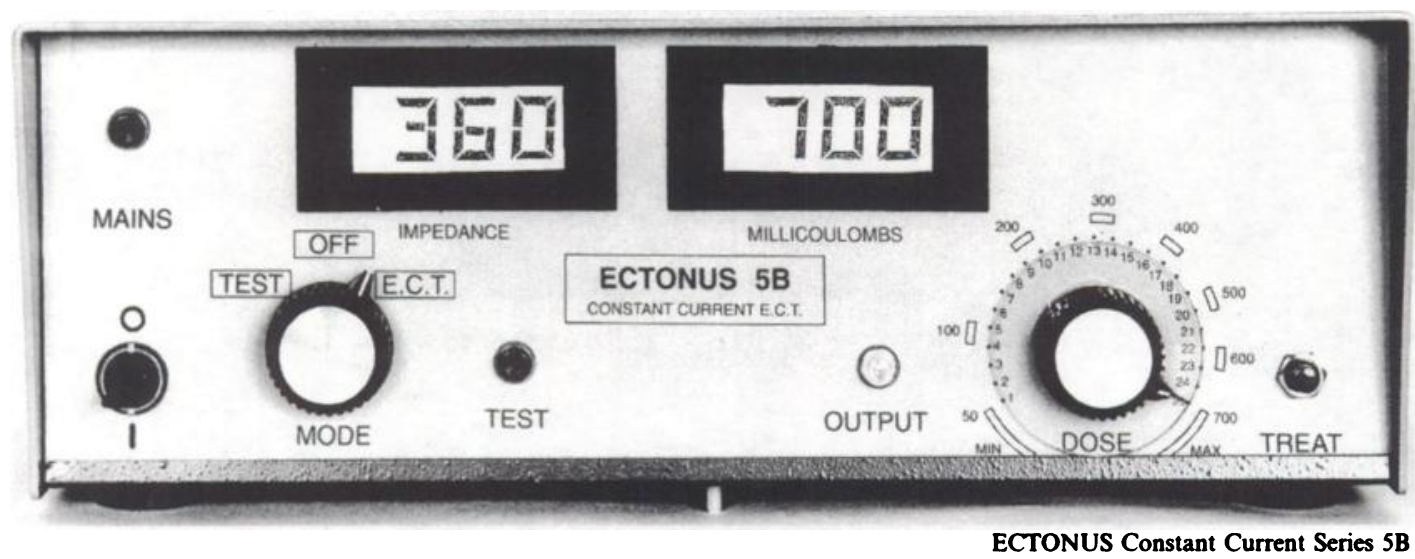

Supplementing the Constant Current Series 5A ECT Apparatus

ECTONUS and ECTONUSTIM models available from the manufacturers with over 48 years of experience in the design of E.C.T. equipment.

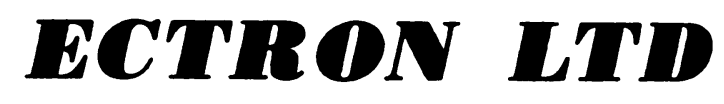

KNAP CLOSE LETCHWORTH HERTS ENGLAND SG61AQ

Telephone $01462682124 \quad$ Fax 01462481463

\section{The Chinese University of Hong Kong}

\section{Faculty of Medicine}

The University (founded 1963) offers comprehensive programmes up to PhD level, with student enrolment over 12,000 . The Faculty of Medicine offers undergraduate and postgraduate programmes in Medicine, Nursing and Pharmacy. The MBChB programme admits 160 students annually. Clinical courses are taught at the Faculty's I,450-bed teaching hospital, the Prince of Wales Hospital (which is one of the regional hospitals in Hong Kong) and at the Lek Yuen Health Centre.

Applications are invited for the following post:

Department of Psychiatry

Senior Lecturer (carrying the academic title of Associate Professor or Professor, as appropriate)

(Ref. $97 / 089(173) / 2$ )

Applicants should have a medical qualification, preferably approved for full registration with the Hong Kong Medical Council; and the FHKAM (Psychiatry) qualification, or the Fellowship or Membership of one of the Royal Colleges of Psychiatrists or their equivalent; as well as ample teaching, clinical and research experience. Ability to conduct clinical work in Cantonese will be an advantage. Appointment will be made on fixed-term contract basis. The appointee is expected to assume duty in July 1998 or as soon as possible thereafter.

Annual Salary and Fringe Benefits

Senior Lecturer (Clinical): HKS $1,320,000$ to $1,626,600$ by 10 increments (approx. exchange rate in October 1997: $£_{1}=H_{K} \$_{12.48}$; US\$ $1=H K \$_{7.8}$ )

Starting salary will be commensurate with qualifications and experience.

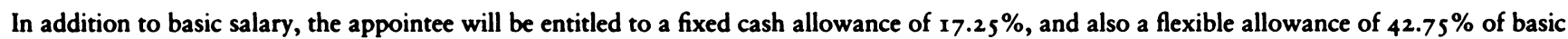
salary as housing assistance subject to the rules for prevention of double housing benefits; other benefits include leave with full pay, medical and dental care and a contract-end gratuity ( $15 \%$ of basic salary) where applicable.

Further information about the University and the general terms of service for staff is available on our World Wide Web homepage <http://www.cuhk.edu.hk>.

\section{Application Procedure}

Please send full resume, copies of academic credentials, a publication list and/or abstracts of selected published papers, together with names and addresses (fax numbers/e-mail addresses as well, if available) of three referees, to the Personnel Office, The Chinese University of Hong Kong, Shatin, N.T., Hong Kong (Fax: $(852) 26036852$ ) on or before December 27, 1997 . Please quote the reference number and mark 'Recruitment' on cover. [Note: The University reserves the right not to fill the post, to fill the post at a lower level or to fill the post by invitation]. 


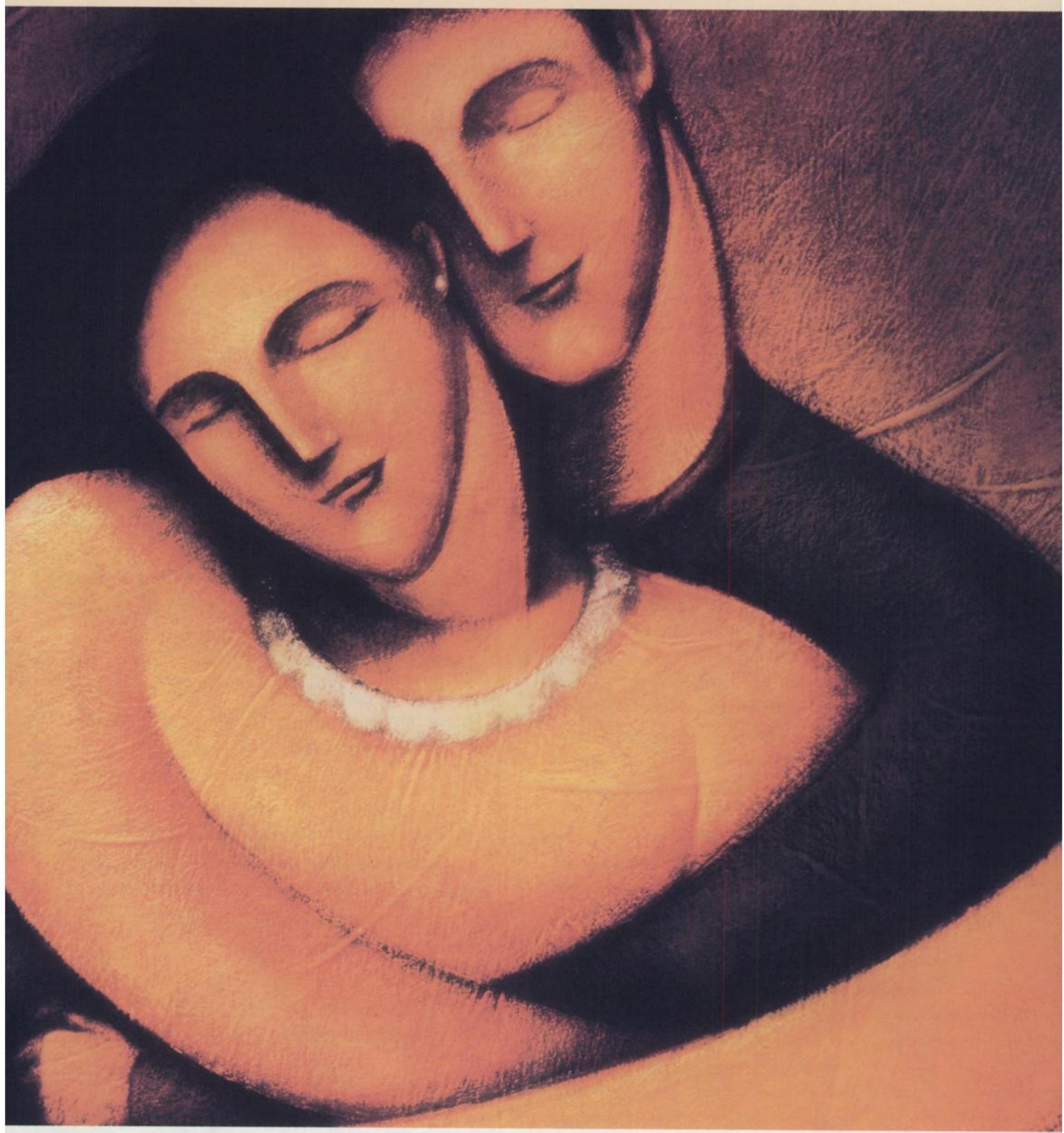

Illustration $\odot$ Janet Atkinson/SIS Paris

\section{Tender loving care and}

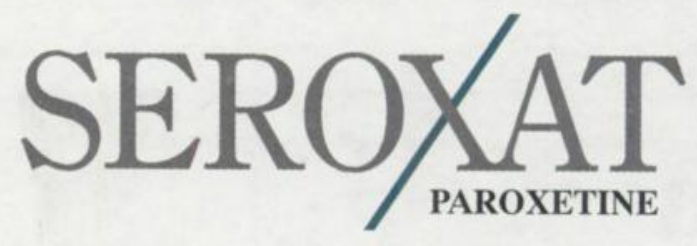

'Seroxat' helps get depressed patients back to normal, liberating them from everyday stresses and anxiety.

For all those depressed patients who need a helping hand to face life again, make 'Seroxat' your first-choice prescription for depression.
Rebuilding the lives of anxious depressed patients 


\section{Prescribing information}

Presentation 'Seroxat' Tablets, PL 10592/0001-2, each containing either 20 or $30 \mathrm{mg}$ paroxetine as the hydrochloride. 30 (OP) $20 \mathrm{mg}$ tablets, $£ 20.77 ; 30$ (OP) $30 \mathrm{mg}$ tablets, £31.16. 'Seroxat' Liquid, PL 10592/0092, containing $20 \mathrm{mg}$ paroxetine as the hydrochloride per $10 \mathrm{ml} .150 \mathrm{ml}(\mathrm{OP}), £ 20.77$. Indications Treatment of symptoms of depressive illness of all types including depression accompanied by anxiety. Treatment of symptoms of obsessive compulsive disorder (OCD). Treatment of symptoms and prevention of relapse of panic disorder with or without agoraphobia. Dosage Adults: Depression: $20 \mathrm{mg}$ a day. Review response within two to three weeks and if necessary increase dose in $10 \mathrm{mg}$ increments to a maximum of $50 \mathrm{mg}$ according to response. Obsessive compulsive disorder: $40 \mathrm{mg}$ a day. Patients should be given $20 \mathrm{mg}$ a day initially and the dose increased weekly in $10 \mathrm{mg}$ increments. Some patients may benef from a maximum dose of $60 \mathrm{mg}$ a day. Panic disorder: $40 \mathrm{mg}$ a day. Patients should be given $10 \mathrm{mg}$ a day initially and the dose increased weekly in $10 \mathrm{mg}$ increments. Some patients may benefit from a maximum dose of $50 \mathrm{mg}$ a day. Give orally once a day in the morning with food. The tablets should not be chewed. Continue treatment for a sufficient period, which may be several months for depression or longer for $\mathrm{OCD}$ and panic disorder. As with many psychoactive medications abrupt discontinuation should be avoided - see Adverse reactions. Elderly: Dosing should commence at the adult starting dose and may be increased in weekly $10 \mathrm{mg}$ increments up to a maximum of $\mathbf{4 0} \mathrm{mg}$ a day according to response. Children: Not recommended. Severe renal impairment (creatinine clearance $<30 \mathrm{ml} / \mathrm{min}$ ) or severe hepatic impairment: $20 \mathrm{mg}$ a day. Restrict incremental dosage if required to lower end of range. Contra-indication Hypersensitivity to paroxetine. Precautions History of mania. Cardiac conditions: caution. Caution in patients with epilepsy; stop treatment if seizures develop. Driving and operating machinery. Drug interactions Do not use with or within two weeks after MAO inhibitors; leave a two-week gap before starting MAO inhibitor treatment. Possibility of interaction with tryptophan. Great caution with warfarin and other oral anticoagulants. Use lower doses if given with drug metabolising enzyme inhibitors; adjust dosage if necessary with drug metabolising enzyme inducers. Alcohol is not advised. Use lithium with caution and monitor lithium levels. Increased adverse effects with phenytoin; similar possibility with other anticonvulsants. Pregnancy and lactation Use only if potential benefit outweighs possible risk. Adverse reactions In controlled trials most commonly nausea, somnolence, sweating, tremor, asthenia, dry mouth, insomnia, sexual dysfunction (including impotence and ejaculation disorders), dizziness, constipation and decreased appetite. Also spontaneous reports of dizziness, vomiting, diarrhoea, restlessness, hallucinations, hypomania, rash including urticaria with pruritus or angioedema, and symptoms suggestive of postural hypotension. Extrapyramidal reactions reported infrequently; usually reversible abnormalities of liver function tests and hyponatraemia described rarely. Symptoms including dizziness, sensory disturbance, anxiety, sleep disturbances, agitation, tremor, nausea, sweating and confusion have been reported following abrupt discontinuation of 'Seroxat'. It is recommended that when antidepressant treatment is no longer required, gradual discontinuation by dose-tapering or alternate day dosing be considered. Overdosage Margin of safety from available data is wide. Symptoms include nausea, vomiting, tremor, dilated pupils, dry mouth, irritability, sweating and somnolence. No specific antidote. General treatment as for overdosage with any antidepressant. Early use of activated charcoal suggested. Legal category POM. 3.3.97

\section{SmothKlono Beccham}

Pharmaceuticals

Welwyn Garden City, Hertfordshire AL7 1EY 'Seroxat' is a registered trade mark. - 1997 SmithKline Beecham Pharmaceuticals
College Seminars

Series from Gaskell
The Psychiatry

of Learning Disabilities

\section{Edited by Oliver Russell}

This volume is both an up to date account of recent advances in the field of learning disabilities and a practical guide to the diagnosis and treatment of psychiatric disorder. Chapters on the classification of psychiatric disorders in people with learning disabilities, the epidemiology of intellectual disability and the diagnosis of psychiatric disorder are followed by more detailed accounts of autism, behavioural phenotypes and communication disorders. Psychiatric disorders are covered in the latter part of the book, including discussions on behavioural interventions, counselling and epilepsy. The book concludes with a review of forensic aspects of psychiatric management and treatment.

Written primarily for trainee and general psychiatrists, this book will also be of use to consultants, paediatricians, nurses and social workers.

1997, 288pp, ISBN $0901242021, £ 15.00$

Gaskell books are available from the Publications Department, Royal College of Psychiatrists, 17 Belgrave Square, London SW1X 8PG (Tel. +44(0)171 235 2351, extension 146). The latest information on College publications is available on the INTERNET at: http://www.demon.co.uk/rcpsych/ 


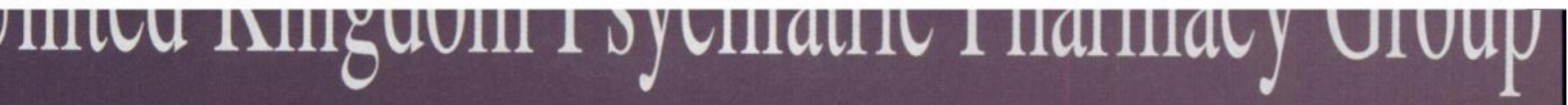

Psychiatric medication helpline for patients and carers.
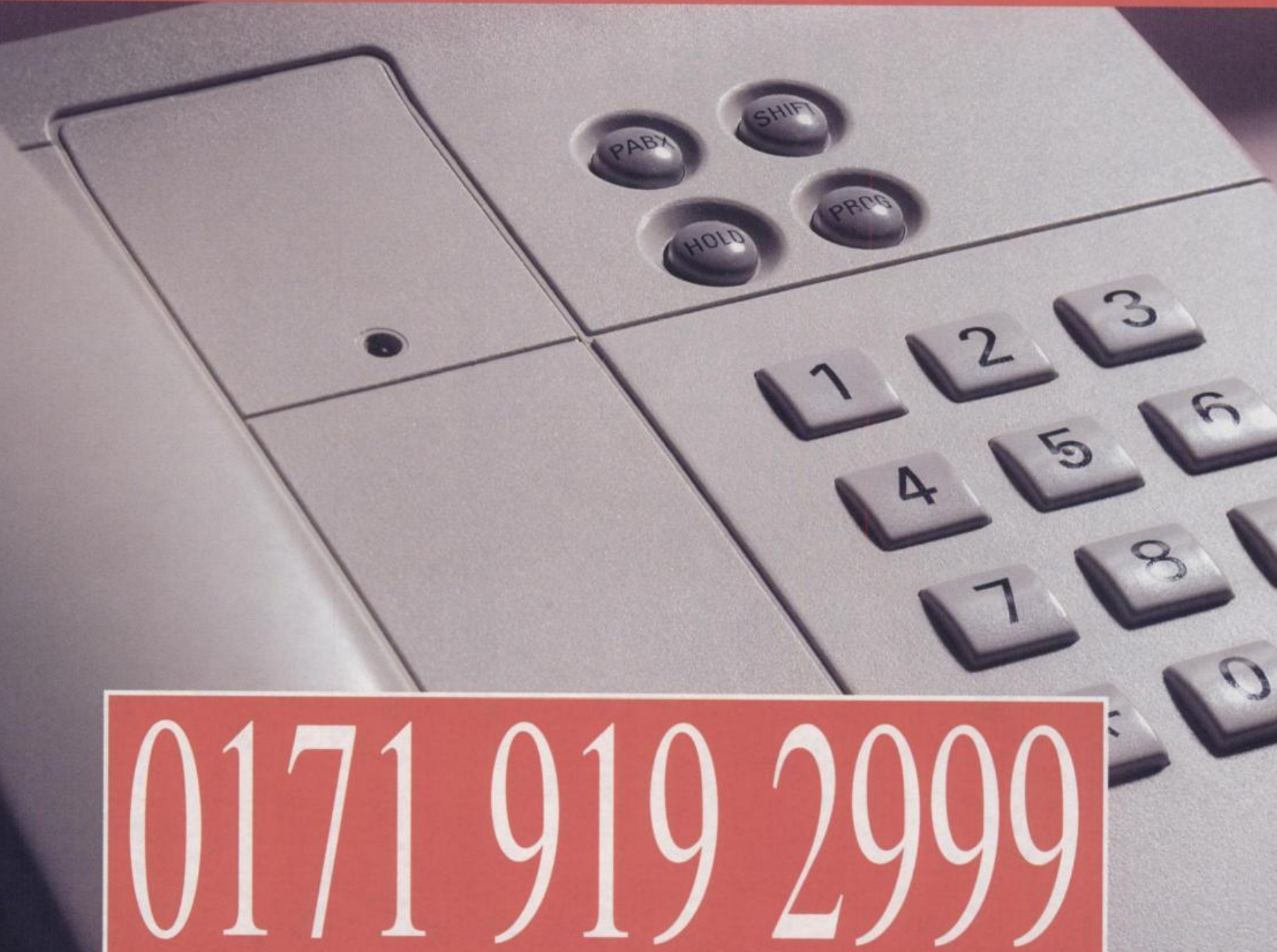

2

3
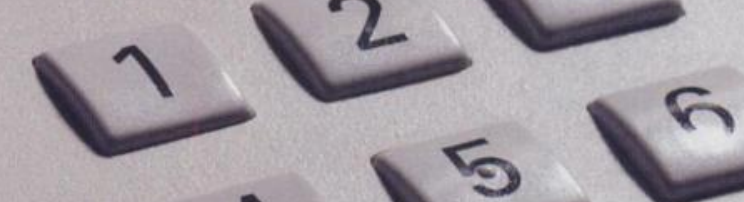

4

Open 11.00am t0 5.00pm. Weekdays only.

This helpline is staffed by experienced pharmavists the Vaudse-thorptia, London.

Patients and carers may telephone with any queries they have about medicines used in psychiatry. 

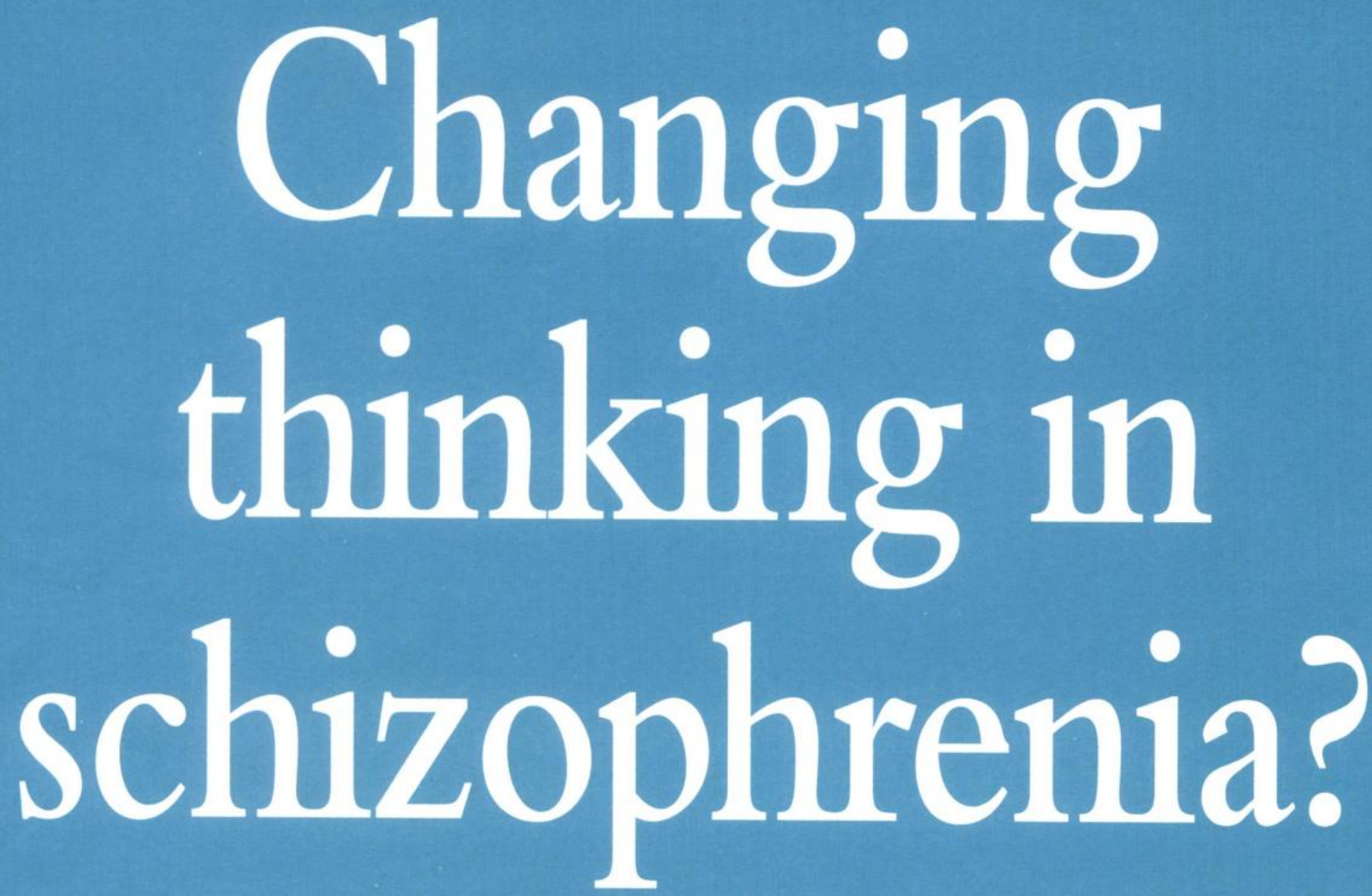

\section{'SEROQUEL' (quetiapine)}

Prescribing Notes.

Consult Summary of Product Characteristics before prescribing. Special reporting to the CSM required.

Use: Treatment of schizophrenia.

Presentation: Tablets containing $25 \mathrm{mg}, 1(0) \mathrm{mg}$ and $200 \mathrm{mg}$ of quetiapine.

Dosage and Administration: 'Seroquel' should be administered twice daily. Adults: The total daily dose for the first 4 days of therapy is 50 $\mathrm{mg}$ (Day 1), $100 \mathrm{mg}$ (Day 2), $200 \mathrm{mg}$ (Day 3) and $300 \mathrm{mg}$ (1)ay 4). From day 4 onwards, titrate to usual effective range of 300 to $450 \mathrm{mg} /$ day. Dose may be adjusted within the range 150 to $750 \mathrm{mg} /$ day acconding to clinical response and tolerability. Elderly patients: Use with caution, starting with $25 \mathrm{mg} /$ day and increasing daily by 25 to $50 \mathrm{mg}$ to an effective dose. Children and adolescents: Safety and efficacy not cvaluated. Renal and hepatic impairment: Start with $25 \mathrm{mg} /$ day increasing daily by 25 to $50 \mathrm{mg}$ to an effective dose. Use with caution in patients with hepatic impairment.

Contra-indications: Hypersensitivity to any component of

the product.
http://doi.org/10.1192/S0007125000149049 Published online by Precautions: Caution in patients with cardiovascular disease. cerebrovascular disease or other conditions predisposing to hypotension and patients with a history of seizures. Caution in combination with drugs known to prolong the QTc interval especially in the elderly. Caution in combination with other centrally acting drugs and alcohol, and on co-administration with thioridazine, phenytoin or other hepatic enzyme inducers, potent inhibitors of CYP3A4 such as systemic ketoconazole or erythromycin. If signs and symptoms of tardive dyskinesia appear, consider dosage reduction or discontinuation of 'Seroquel'. In cases of neuroleptic malignant syndrome, discontinue 'Seroquel' and give appropriate medical treatment. 'Seroquel' should only be used during pregnancy if benefits justify the potential risks. Avoid breastfeeding whilst taking 'Seroquel'. Patients should be cautioned about operating hazardous machines, including motor vehicles.

Undesirable events: Sonnolence, dizziness, constipation, postural hypotension, dry mouth, asthenia, rhinitis, dyspepsia, limited weight gain, orthostatic hypotension (associated with dizziness), tachycardia and in some patients syncope.

Occasional seizures and rarely possible neuroleptic malignant syndrome. Transient leucopenia and/or neutropenia and occasionally eosinophilia. Asymptomatic, usually reversible elevations in serum transaminase or gamma - GT levels. Sinall clevations in non-fasting serum triglyceride levels and total cholesterol. Decreases in thyroid hormone levels, particularly total T4 and free T4 usually reversible on cessation.
Legal category: POM

Product licence numbers:

25 mg tablet: $12619 / 0112$

$100 \mathrm{mg}$ tablet: $12619 / 0113$

$200 \mathrm{mg}$ tablet: $12619 / 0114$

Basic NHS cost:

Starter pack $£ 6.59 ; 60 \times 25 \mathrm{mg}$ tablets $£ 28.20$;

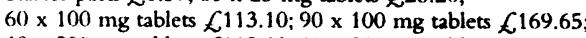
$60 \times 20() \mathrm{mg}$ tablets $£ 113.10 ; 90 \times 200 \mathrm{mg}$ tablets $f_{169.65}$

'Seroquel' is a trademark, the property of Zeneca Limited. Further information is available from:

ZENECA Pharma on 0800200123 please ask for Medical Information, or write to King's Court, Water Lane, Wilmslow, Cheshire SK9 5AZ.

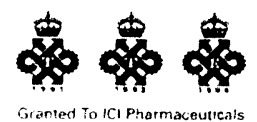




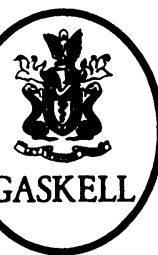

College

SEMINARS

SERIES

College Seminars is a series of textbooks covering the breadth of psychiatry. As well as helping junior doctors during their training years, College Seminars will make a contribution to the continuing medical education of established clinicians.

\section{NEW Seminars in the Psychiatry of Learning Disabilities}

Edited by Oliver Russell

This volume is both an up to date account of recent advances in the field of learning disabilities and a practical guide to the diagnosis and treatment of psychiatric disorder. Chapters on the classification of psychiatric disorders in people with learning disabilities, the epidemiology of intellectual disability and the diagnosis of psychiatric disorder are followed by more detailed accounts of autism, behavioural phenotypes and communication disorders. Psychiatric disorders are covered in the latter part of the book, including discussions on behavioural interventions, counselling and epilepsy. The book concludes with a review of forensic aspects of psychiatric management and treatment.

£15.00, 282pp, 1997, ISBN $0901242021, £ 15.00$

\section{Seminars in Psychiatric Genetics}

By P. McGuffin, M.J. Owen, M.C. O'Donovan, A. Thapar \& 1.I. Gottesman

Comprehensive coverage of what is known of the genetics of psychiatric disorders, and an introduction to the relevant quantitative and molecular genetic methods.

£10.00, 240pp, 1994, ISBN 902241656

\section{Seminars in Alcohol and Drug Misuse}

Edited by Jonathan Chick \& Roch Cantwell

A clear review of the aetiology, epidemiology, treatment and prevention of dependence on and misuse of alcohol and illicit and prescribed drugs is presented. With a balance of theory, recent research and practical clinical guidelines, the book covers specific and common problems in mental health as well as in general medicine.

E13.50, 246pp, 1994, ISBN 0902241702

\section{Seminars in Practical Forensic Psychiatry}

Edited by Derek Chiswick \& Rosemary Cope

A concise account of the specialty from a strongly practical perspective. This book systematically describes the relationship between psychiatric disorders and offending, with detailed discussion of the criminal justice system, court proceedings, mental health legislation, dangerousness, prison psychiatry, and civil issues. It is up-to-date, with references to the Reed report, the Clunis Inquiry, supervision registers and recent legislation. Career guidance and a chapter on ethical issues are included.

E17.50, 359pp, 1995, ISBN 0902241788

\section{Seminars in Clinical Psychopharmacology}

\section{Edited by David J. King}

Linking relevant basic neuropharmacology to clinical practice, this book is an excellent introduction to an ever-expanding and fascinating subject. It aims to bridge the gap between the theoretical basis for the mode of action of psychotropic drugs and guidance on the clinical standing of the drugs widely used in medical practice.

£20.00, 544pp, 1995, ISBN 0902241737

\section{Seminars in Liaison Psychiatry}

\section{Edited by Elspeth Guthrie \& Francis Creed}

Moving from the psychiatric in-patient and out-patient settings to the general medical wards can be disorientating and difficult. The clinical problems are different. In this text, recognised experts in liaison psychiatry guide the trainee through the various difficulties of interviewing, assessing and formulating the psychological problems found in patients in general medical units.

\{15.00, 312pp, 1996, ISBN 0902241958

\section{Other books in the series}

Seminars in Basic Neurosciences

£15.00, 336pp, 1993, ISBN 0902241613

Seminars in Psychology and the Social Sciences

E17.50, 358pp, 1994, ISBN 0902241621

Seminars in Child and Adolescent Psychiatry

₹15.00, 298pp, 1993, ISBN0902241559

\section{Titles in preparation}

Adult Psychiatric Disorders

Autumn 1997

Gaskell is the imprint of the Royal College of Psychiatrists. The books in this series and other College publications are available from good bookshops and from the Booksales Office, Publications Department, Royal College of Psychiatrists, 17 Belgrave Square, London SW1X 8PG. Credit card orders can taken over the telephone (+44(0)171 2352351 , extension 146). The latest information on Gaskell publications is available on the College website at: www.rcpsych.ac.uk 

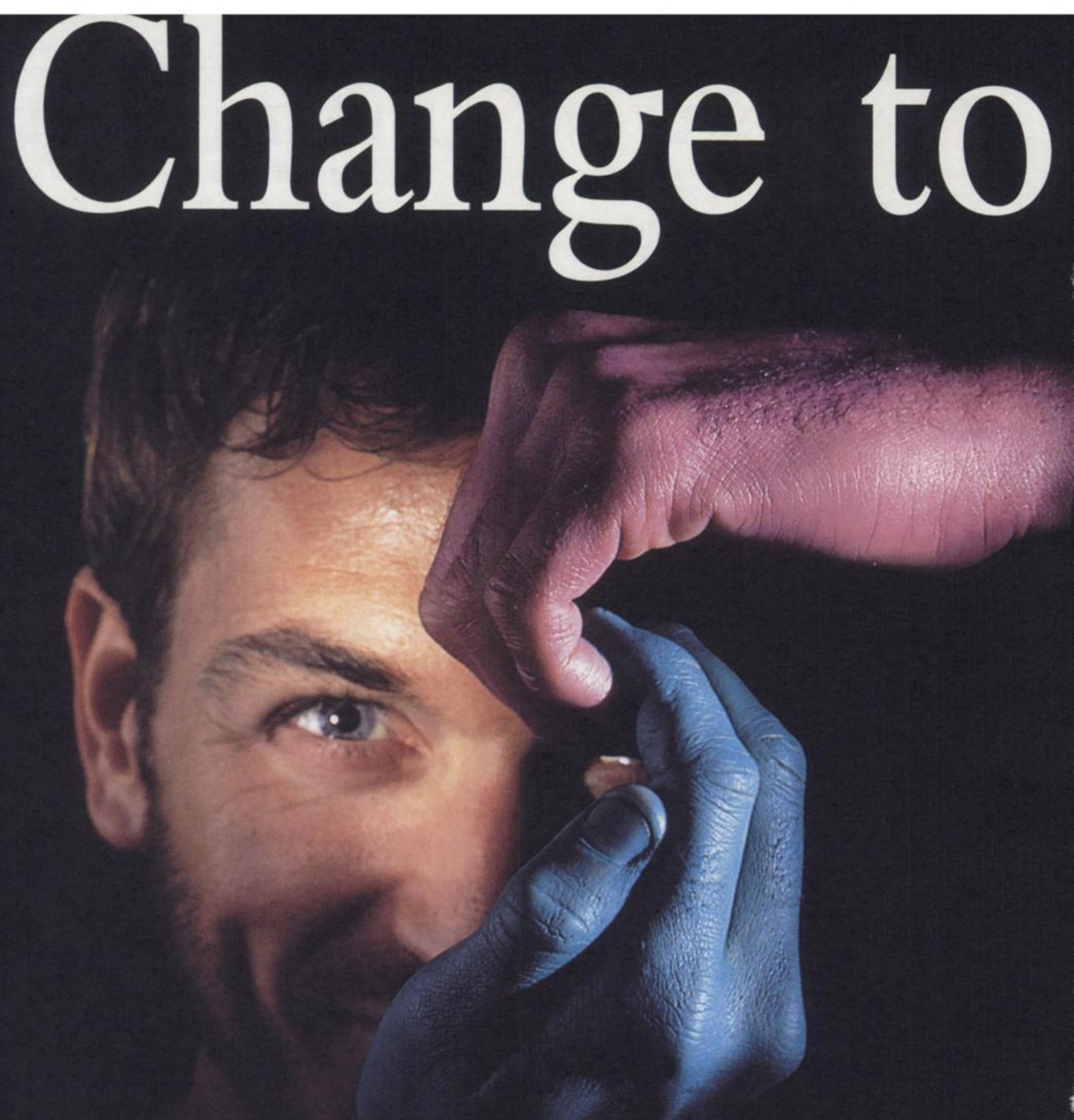

\section{'SEROQUEL' (quetiapine)}

Prescribing Notes.

Consult Summary of Product Characteristics before prescribing. Special reporting to the CSM required. Use: Treatment of schizophrenia.

Presentation: Tablets containing $25 \mathrm{mg}, 100 \mathrm{mg}$ and $200 \mathrm{mg}$ of quetiapine.

Dosage and Administration: 'Seroguel' should be administered twice daily. Adults: The total daily dose for the first 4 days of therapy is $50 \mathrm{mg}$ (Day 1), $100 \mathrm{mg}$ (Day 2), $200 \mathrm{mg}$ (Day 3) and $300 \mathrm{mg}$ (Day 4). From day 4 onwards. titrate to usual effective range of 300 to $450 \mathrm{mg} /$ day. Dose max be adjusted within the range 150 to $750 \mathrm{mg} / \mathrm{d}$ y
Elderly patients: Use with caution, starting with $25 \mathrm{mg} /$ day and increasing daily by 25 to $50 \mathrm{mg}$ to an effective dose: Children and adolescents: Safety and efficacy not evaluated. Renal and hepatic impairment: Start with $25 \mathrm{mg} /$ day increasing daily by 25 to $50 \mathrm{mg}$ to an effective dose. Use with caution in patients with hepatic impairment.

Contra-indications: Hypersensitivity to any component of the product.

Precautions: Caution in patients with cardiovascular disease, cerebrovascular disease or other conditions predisposing to hypotension and patients with a history of seizures. Caution in combination with drugs known to prolong the QTC interval, especially in the elderly. Caution in combination with other centrally acting drugs and alcohol, and on coadrninistration with thioridazine, phenytoin or other hepatic systemic ketoconazole or erythromycin. If signs and symptoms of tardive dyskinesia appear, consider dosage reduction or discontinuation of 'Seroquel'. In cases of neuroleptic malignant syndrome, discontinue 'Seroquel' and give appropriate medical treatment. 'Seroquel' should only be used during pregnancy if benefits justify the potential risks. Avoid breastfeeding whilst taking 'Seroquel'. Patients should be cautioned about operating hazardous machines, including motor vehicles.

Undesirable events: Somnolence, dizziness, constipation, postural hypotension, dry mouth, asthenia, rhinitis, dyspepsia,
limited weight gain, orthostatic hypotension (associated with dizziness), tachycardia and in some patients syncope.

Occasional seizures and rarely possible neuroleptic malignani syndrome. Transient leucopenia and/or neutropenia and

occasionally eosinophilia. Asymptomatic, usually reversible 


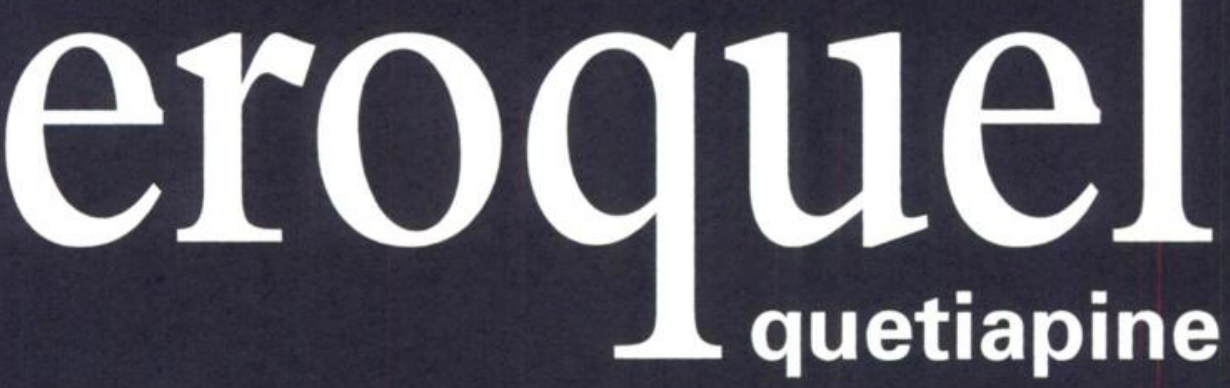

5 Effective in positive and negative symptoms ${ }^{1-4}$ and improving $\operatorname{mood}^{\star 5}$ in patients with schizophrenia

6 Incidence of EPS no different from placebo across the full dose range ${ }^{1-4}$

Rate of withdrawals due to adverse events no different from placebo $^{6}$

No requirement for routine blood, BP or ECG monitoring ${ }^{7}$

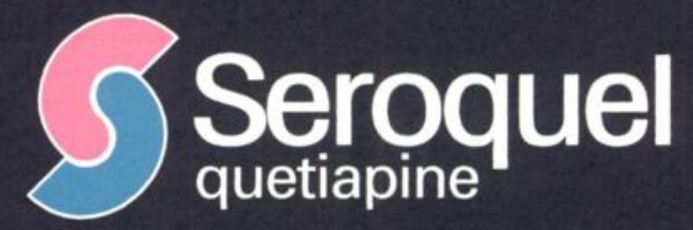

Changing thinking in schizophrenia.

* Defined as the BPRS item scores of depressive mood, anxiety, guilt feelings and tension

Small elevations in non-fasting serum triglyceride levels and teal cholesterol. Decreases in thyroid hormone levels. particularly total T4 and free $\mathrm{T} 4$ usually reversible on cessation. Prolongation of the QTc interval (in clinical trials his was not associated with a persistent increase).

(1.egal category: POM

Product licence numbers:

5 mg tablet: $12619 / 0112$

fin mi tablet: $12619 / 0113$

fo mg tablet: 12619/0114

3asic NHS cost:

Starter pack $6.59 \% 60 \times 25 \mathrm{mg}$ tablets 28.20 :

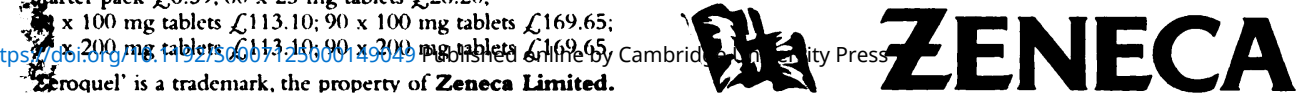

Furcher information is available from:

ZENECA Pharma on 0800200123 please ask for

Medical Information, or write to King's Court.

Water Lane, Wilmslow, Cheshire SK9 $5 \mathrm{AZ}$

Witer
References

1. Fabre LF, Arvanitis L, Pultz J et al. Clin Ther 1995;

17 (No.3): 366-378

2. Arvanitis LA et al. Biol Psychiatry 1997; 42: 233-246. 3. Small JG, Hirsch SR, Arvanitis LA et al. Arch Gen

Psychiatry 1997; 54: 549-557.

4. Borison RL, Arvanitis LA, Miller MS et al. J Clin Psychopharmacol 1996; 16 (2):158-169. 5. Data on File, Zenaca Pharmaceuticals.

6. Data on File, Zeneca Pharmaceuticals.

7.'Seroquel' Summary of Product Characteristics. 


\section{Seminars in NEW! \\ General Adult Psychiatry Edited by George Stein \& Greg Wilkinson}

A major new textbook of adult general psychiatry by leading experts in the field and the centrepiece of the Seminars series. This multi-authored textbook places its greatest emphasis on detailed clinical descriptions of the common psychiatric disorders and their place within the ICD-10 and DSM-IV schemes. Psychological and biological treatments are covered in depth giving the reader an insight into the issues involved in modern patient care. Although primarily intended for doctors preparing for their MRCPsych, the text provides a comprehensive well-referenced review of the whole of modern clinical psychiatry and will be of use to consultant psychiatrists and other health professionals in the mental health field. As with other titles in the series, frequent use of boxes, tables and figures is made to set out important points and key information. The book is presented in two volumes as a boxed set.

$\bullet £ 55.00 \bullet$ Vol 1: 810pp Vol 2: 698pp • Published January $1998 \bullet$ ISBN 0902241915

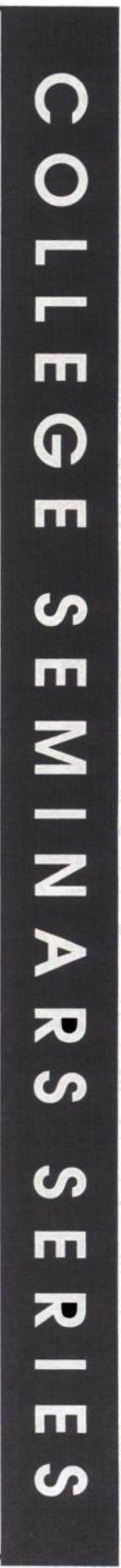

\section{CONTENTS}

Volume 1 Foreword - Preface - Clinical features of depressive disorders $\bullet$ Mania, bipolar disorder and treatment

- The causes of depression - Drug treatment of depression

- Electroconvulsive therapy and other treatments -

Psychological treatment of depression - Schizophrenia the clinical picture - The aetiology of schizophrenia The psychological and social management of schizophrenia - Schizoaffective, paranoid and other psychoses - Suicide and deliberate self-harm - Anxiety disorders - Phobic disorders - Obsessive-compulsive disorder - Hysteria • Hypochondriasis and other somatoform disorders • Index

Volume 2 Foreword - Preface - Personality disorders - Treatment and outcome of the personality disorders • Anorexia nervosa and bulimia nervosa - Postpartum and related disorders - Organic psychiatric disorders • Psychiatric aspects of neurological disorders - Toxic, metabolic and endocrine disorders - Sleep disorders • Diagnosis, classification and measurement $\bullet$ Mental health services - Psychiatry in general practice - Index

\section{How to order}

The books in this series and other College publications are available from good bookshops and from Book Sales, Publications Department, Royal College of Psychiatrists, 17 Belgrave Square, London SWIX 8PG. Credit card orders can taken over the telephone $(+44(0) 1712352351$, extension 146). The latest information on Gaskell publications is available on the College website at: www.rcpsych.ac.uk

\section{Other titles in the series}

Seminars in the Psychiatry of Learning Disabilities Edited by Oliver Russell

f15.00, 282pp, 1997, ISBN 0901242021

Seminars in Psychiatric Genetics

By P. McGuffin, M.J. Owen, M.C. O'Donovan,

A. Thapar \& I.I. Gottesman

f10.00, 240pp, 1994, ISBN 902241656

Seminars in Alcohol and Drug Misuse

Edited by Jonathan Chick \& Roch Cantwell

f13.50, 246pp, 1994, ISBN 0902241702

Seminars in Practical Forensic Psychiatry

Edited by Derek Chiswick \& Rosemary Cope

f17.50, 359pp, 1995, ISBN 0902241788

Seminars in Clinical Psychopharmacology

Edited by David J. King

£20.00, 544pp, 1995, ISBN 0902241737

Seminars in Liaison Psychiatry

Edited by Elspeth Guthrie \& Francis Creed

f15.00, 312pp, 1996, ISBN 0902241958

Seminars in Basic Neurosciences

Edited by Gethin Morgan \& Stuart Butler

f15.00, 336pp, 1993, ISBN 0902241613

Seminars in Psychology and the Social Sciences

Edited by Digby Tantam \& Max Birchwood

f17.50, 358pp, 1994, ISBN 0902241621

Seminars in Child and Adolescent Psychiatry

Edited by Dora Black \& David Cottrell

f15.00, 298pp, 1993, ISBN 0902241559

Titles in preparation

Seminars in the Psychiatry for the Elderly

Edited by Rob Butler \& Brice Pitt

Seminars in Psychotherapy

Edited by Sandra Grant \& Jane Naismith 